\title{
1 Physiological and molecular responses to combinatorial iron and phosphate 2 deficiencies in hexaploid wheat seedlings
}

3 Gazaldeep Kaur ${ }^{1,2^{*}}$, Vishnu Shukla ${ }^{1 *}$, Varsha Meena ${ }^{1}$, Anil Kumar ${ }^{1,2}$, Deepshikha Tyagi ${ }^{1}$,

4 Jagtar Singh ${ }^{2}$, Pramod Kaitheri Kandoth ${ }^{1}$, Shrikant Mantri ${ }^{1}$, Hatem Rouached ${ }^{3,4}$, and Ajay

5 Kumar Pandey ${ }^{1 \#}$

6

7 Author affiliations

$8{ }^{1}$ National Agri-Food Biotechnology Institute (Department of Biotechnology), Sector 81,

9 Knowledge City, Mohali-140306, Punjab, India.

$10{ }^{2}$ Department of Biotechnology, Panjab University, Punjab, India.

$11{ }^{3}$ Department of Plant, Soil, and Microbial Sciences, Michigan State University, East Lansing,

12 MI 48824

$13{ }^{4}$ Plant Resilience Institute, Michigan State University, East Lansing, MI 48824

14 *Both the authors contributed equally

$16{ }^{\#}$ Corresponding author

17 Dr. Ajay K Pandey, Scientist-F.

18 National Agri-Food Biotechnology Institute (Department of Biotechnology), Sector 81,

19 Knowledge City, Mohali-140306, Punjab, India.

20 Telephone: +91-1724990124

21 Email: $\quad$ pandeyak@nabi.res.in; pandeyak1974@gmail.com

22 ORCID iD: https://orcid.org/0000-0003-1064-139X

24 Running title: Fe and P cross-talk in hexaploid wheat 


\section{HIGHLIGHTS}

62 KEYWORDS: iron, phosphate, Triticum aestivum, nutrient homeostasis, growth,

63 transcriptome.

- This study was performed to understand the molecular changes occurring during the interaction of Phosphorus (P) and Iron (Fe) in hexaploid wheat roots.

- $\quad \mathrm{P}$ and Fe show cross-talk as Fe deficiency-induced phenotype that was restored by the withdrawal of $\mathrm{P}$.

- A total of 2780 differentially expressed genes were identified in the roots with the combined $-\mathrm{Fe}-\mathrm{P}$ deficiencies with predominance for UDP-glycosyltransferases, cytochrome-450 and glutathione-S-transferases transcripts.

- The metabolomic changes identified the importance of amino-isobutyric acid, arabinonic acid and aconitic acid during dual deficiency

- This work provides a comprehensive insight to understand the molecular rearrangements occurring in wheat roots during Fe and $\mathrm{P}$ interaction.

\section{ABSTRACT}

Iron $(\mathrm{Fe})$ and phosphorus $(\mathrm{P})$ are the essential mineral nutrient for plant growth and development. However, the molecular interaction of the Fe and P pathways in crops remained largely obscure. In this study, we provide a comprehensive physiological and molecular analysis of hexaploid wheat response to single $(\mathrm{Fe}, \mathrm{P})$ and its combinatorial deficiencies. Our data showed that inhibition of the primary root growth occurs in response to Fe deficiency; however, growth was rescued when combinatorial deficiencies occurred. Analysis of RNAseq revealed that distinct molecular rearrangements during combined deficiencies with predominance for genes related to metabolic pathways and secondary metabolite biosynthesis primarily include genes for UDP-glycosyltransferase, cytochrome-P450s, and glutathione metabolism. Interestingly, the Fe-responsive cis-regulatory elements in the roots in Fe stress conditions were enriched compared to the combined stress. Our metabolome data also revealed the accumulation of distinct metabolites such as amino-isobutyric acid, arabinonic acid, and aconitic acid in the combined stress environment. Overall, these results are essential in developing new strategies to improve the resilience of crops in limited nutrients. 


\section{Introduction}

66 Nutrient deficiencies in the rhizospheric environment of the plants severely reduce crop yields

67 and negatively affect the worldwide food supply [1]. Iron (Fe) is an essential microelement for

68 plant growth and development and is utilized in nearly every cellular process, including

69 photosynthesis and respiration. In general, deficiency of Fe is considered as one of the most

70 critical limitations in cereal crop production, especially in alkaline calcareous soil [2,3].To

71 overcome $\mathrm{Fe}$ deficiency, non-graminaceous and graminaceous species rely on different

72 strategies for transporting the available Fe. The strategy I is used by non-graminaceous plants

73 wherein the lowering of rhizospheric $\mathrm{pH}$ is attained through excretion of protons with P-type

74 ATPases coupled with Ferric reductase oxidase activity at the root plasma membrane, thereby

75 causing reduction of $\mathrm{Fe}^{3+}$ to $\mathrm{Fe}^{2+}$, thereby making bioavailable to plant [4]. The uptake of $\mathrm{Fe}^{2+}$

76 is done by the divalent transporter Iron-regulated transporter (IRT1) [5,6]. Graminaceous plants

77 rely on Strategy II, which uses chelation for Fe absorption, predominately through biosynthesis

78 and secretion of phytosiderophores (PS), such as mugineic acids (MAs). These biochemicals

79 make Fe-PS complexes that are subsequently transported into the roots by yellow stripe-like

80 transporter proteins (YSL) [7-12]. The molecular players involved in the efflux of MA are now

81 characterized in rice, barley and very recently identified in wheat [11,12]. Regulation of Fe

82 acquisition, transport and mobilization mainly involve central transcription factors (TFs)

83 belonging to the family of basic helix-loop-helix (bHLH), $\mathrm{Fe} \square$ deficiency $\square$ responsive elements

84 binding factors (IDEF1 and IDEF2) and IRO2/IRO3 [13-17].

85 Phosphorus $(\mathrm{P})$ is an essential macronutrient for plants to complete their life cycle. The

$86 \mathrm{P}$ deprivation typically results in root architecture changes to enhance its uptake and

87 mobilization [18,19]. Under low P concentrations, the model plant Arabidopsis (Col-0) show

88 reduced primary root elongation. This phenotype was proposed to be partly due to Fe toxicity

89 at the root tip. Unlike Arabidopsis, most monocot plants, including maize, rice and wheat,

90 showed either no reduction or slight elongation of primary roots under P deficiency [20-22]. In

91 contrast, no Fe toxicity was reported in cereal crops grown under P deficient condition. Thus,

92 how monocots (esp. cereal crops) coordinate $\mathrm{P}$ and Fe remains largely unknown. Based on the

93 available information, the key components involved in adapting to $\mathrm{P}$ deficiency include the

94 transcription factor (TF) PHOSPHATE STARVATION RESPONSE

95 (PHR1); microRNA399 (miR399); PHOSPHATE1 (PHO1), SPX containing proteins, and

96 ubiquitin E2-conjugase(PHO2) are functionally conserved in Arabidopsis (dicots), rice and

97 wheat [23-25]. During the P deficiency, genes response is regulated by the TF (PHR1) though 
98 cis-elements PHR1 binding site (P1BS motif) present in their promoters. Overall, this suggests

99 that roots undergo molecular reprogramming to cope with the nutrient stress.

100 When $\mathrm{P}$ and $\mathrm{Fe}$ are absorbed simultaneously, their availability is still affected by 101 precipitation [26]. Multiple studies have provided preliminary insights into the interaction of $\mathrm{P}$ 102 with the absorption of essential micronutrients like Fe [27,28]. Earlier studies have shown that

$103 \mathrm{P}$ deficiency could promote iron content and storage in Arabidopsis tissue. This suggests that

$104 \mathrm{Fe}$ is more accessible in the rhizosphere under $\mathrm{P}$ deficiency, which leads to reduced expression 105 of Fe homeostasis-related genes [18,29,30]. Interestingly, genes such as ferritin and zinc106 regulated, iron-regulated transporter-like proteins (ZIP) were speculated to be involved in 107 enhancing Fe content in Arabidopsis [17,14,34]. The single nutrient deficiency ( $\mathrm{P}$ and Fe) 108 response has primarily been undertaken, but the simultaneous dual deficiency response 109 remained limited only to Arabidopsis and rice [20]. In addition to this, the P deficiency also 110 causes multiple biochemical and molecular changes that are also involved in Fe and Zinc ( $\mathrm{Zn}$ ) 111 metabolism [32]. Genome-wide information was generated that revealed multiple protein112 encoding genes from roots showing the overlap between Fe and P deficiency response [33]. 113 Also, at the biochemical level, the dual deficiency also regulates the type of metabolites, 114 including selective coumarins that are secreted by the plants [27]. Therefore, the detailed 115 understanding between $\mathrm{P}$ and $\mathrm{Fe}$ homeostasis could provide a powerful tool to conduct 116 molecular studies on nutrient signalling cross-talk for addressing the changing environmental 117 scenarios for crop productivity [34].

118 Wheat is an important crop and is the major source of nutrition. Studying the molecular 119 attributes of Fe and P cross-talk will help in designing a suitable model to optimize crop 120 productivity during nutrient deficiency. In the current study, we performed a comprehensive 121 analysis of physiological, transcriptional and metabolic changes during the combinatorial 122 deficiencies of $\mathrm{Fe}$ and $\mathrm{P}(-\mathrm{Fe}-\mathrm{P})$. An important role of genes involved in Fe uptake under the 123 presence and absence of $\mathrm{P}$ was observed. Our work utilizes physiological and molecular 124 evidences that identifies the distinct transcriptional and metabolic regulation in the roots of 125 wheat during Fe and P interaction. Knowledge gained in this study expands our understanding 126 of single and simultaneous nutrient stresses in cereal crops that are coordinated at the whole 127 plant level. 
131 Indian hexaploid wheat variety, 'C-306', a landrace genotype is known for its superior chapatti

132 quality, was used for this study [35]. The 'C-306' seedlings were grown hydroponically under

133 the Hoagland's nutrient solution containing $\left(\mathrm{L}^{-1}\right): 6 \mathrm{mM} \mathrm{KNO}_{3}, 1 \mathrm{mM} \mathrm{MgSO}{ }_{4} .7 \mathrm{H}_{2} \mathrm{O}, 2 \mathrm{mM}$

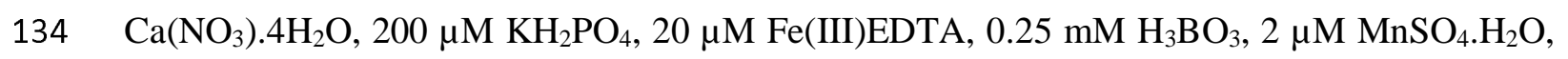

$1352 \mu \mathrm{M} \mathrm{ZnSO} 4.7 \mathrm{H}_{2} \mathrm{O}, 0.5 \mu \mathrm{M} \mathrm{CuSO}_{4} .5 \mathrm{H}_{2} \mathrm{O}, 0.5 \mu \mathrm{M} \mathrm{Na} \cdot \mathrm{MoO}_{4}$ and $0.05 \mathrm{mM}$ KCL. After

136 overnight stratification at $4{ }^{\circ} \mathrm{C}$, wheat seeds were germinated for 5 days in moist (MiliQ water)

137 filter paper. Once the endosperm starts browning, it is removed from the developing seedlings.

138 Seedlings were then transferred to PhytaBox ${ }^{\mathrm{TM}}$ and grown in the nutrient solution described

139 above. After 7 days, nutrient solutions were replaced on the basis of different treatments. For

$140+\mathrm{Fe}-\mathrm{P}$ treatment, $20 \mu \mathrm{M} \mathrm{KH}_{2} \mathrm{PO}_{4}$ was used that was shown earlier for P deficiency [36]. For -

$141 \mathrm{Fe}+\mathrm{P}$ treatment, $2 \mu \mathrm{M}$ Fe (III) EDTA was used for Fe deficiency [12]. While for -Fe-P

142 treatment, $20 \mu \mathrm{M} \mathrm{KH} \mathrm{PO}_{4}$ and $2 \mu \mathrm{M}$ Fe (III) EDTA were used. Control plants $(+\mathrm{Fe}+\mathrm{P})$ were

143 grown in the above-listed concentrations of Hoagland's solution. Plants were grown in the

144 described medium for 20 days in a growth chamber set at $20 \square \pm \square 1 \square{ }^{\circ} \mathrm{C}, 50-70 \%$ relative

145 humidity and photon rate of $300 \square \mu$ mol quanta $\mathrm{m}^{-2} \mathrm{~s}^{-1}$ with $16 \square \mathrm{h} \square$ day/8 $\square \mathrm{h}$ night cycle.

146 The whole set of experiments was repeated four times to examine biological variation. For

147 sampling, all the roots and shoots were collected post 20 days after treatment (DAT; at the

148 Zadoks growth scale, Z15) and at two hours after the onset of light. Samples were snap-frozen

149 in liquid nitrogen and stored at $-80^{\circ} \mathrm{C}$. To characterize the primary root and $1^{\text {st }}$ order lateral

150 root, eight individual plants of each of the three replicates were moved onto $150 \mathrm{~mm}$ wide petri-

151 plates filled with distilled water and examined manually.

\subsection{RNASeq experiment design and sequencing}

154 Total RNA extraction was done using twenty-day old root tissue samples for the four 155 conditions $(+\mathrm{Fe}+\mathrm{P},+\mathrm{Fe}-\mathrm{P},-\mathrm{Fe}+\mathrm{P}$ and $-\mathrm{Fe}-\mathrm{P})$. In total, three biological replicates derived from 156 at least three independent events were sampled for RNA extraction. Each biological replicate 157 consisted of 12-15 seedlings per treatment. Samples were collected at the same time, snap158 frozen in liquid nitrogen and stored at $-80^{\circ} \mathrm{C}$. The RNA extraction and Illumina sequencing 159 were performed with three replicates for $-\mathrm{P}$ and three replicates for $-\mathrm{Fe}-\mathrm{P}$ with their respective 160 controls. For Fe deficiency, previously published RNAseq datasets were used [12]. All the 161 treatments to the seedlings were carried out during the same time, although the analysis was 162 carried earlier from -Fe+P RNA samples. RNA extraction for library construction from the 163 control and treated root samples were performed as reported previously [12]. Briefly, sequence 164 libraries were prepared from high quality, quality-control passed RNA samples using Illumina 
165 TruSeq mRNA library prep kit as per the instructions (Illumina Inc., USA). The reads were 166 sequenced using $2 \times 150$ bp chemistry on NextSeq 500 and NovaSeq 6000. Only one 167 biological replicate for $-\mathrm{P}$ did not generate the desired output data size; therefore, only two 168 replicate data sets were used for subsequent analysis. These replicates were validated for their 169 conserved P deficiency response as noted previously [24] before proceeding for study.

\subsection{Sample clustering and differential expression analysis}

172 Paired-end reads were quality trimmed and adapter filtered using Trimmomatic v0.35 to retain 173 only good quality reads $(\mathrm{QV}>20)$. The clean raw reads were quantified for expression by 174 pseudoalignment against wheat transcriptome (ensembl release 46; 175 ftp://ftp.ensemblgenomes.org/pub/plants/release-46/fasta/triticum_aestivum/ /IWGSC RefSeq $176 \mathrm{v} 1.0$ ) using Kallisto v0.44.0 [37] and the option --rf-stranded for stranded samples. DESeq2 R 177 package [38] was used for differential expression analysis. Raw count values from Kallisto 178 were summarized from transcript to gene-level abundances and imported for use with DESeq2 179 using tximport package [39]. Principal Component Analysis (PCA) and clustered heatmap 180 analysis was performed based on VST transformed counts for the top 500 genes showing 181 highest variation in expression to observe clustering across replicates and conditions. The 182 representatives from batches were taken together to build a DESeq2 model to obtain 183 normalised counts, which were transformed using VST mode and corrected for the associated 184 batch effect using remove Batch Effect function from limma package [40]. The ggplot2 [41] 185 and pheatmap package were used to design the PCA plot and clustered heatmap, respectively.

186 The DESeq() function was used for differential expression analysis to calculate a 187 relative expression for pairwise comparisons among conditions. $\log _{2}$ Fold Changes (Log2FC) 188 were obtained for the pairwise comparisons for each of the three deficiency conditions and the 189 control $(+\mathrm{Fe}+\mathrm{P})$ from the respective batch group only to further avoid any variation due to 190 batch effects. The relative expression ratios were shrunk using apeglm package [42] to adjust 191 the Log2FC of genes with extremely low counts. The percentage for genes with similar expression changes (overlapping DEG percentage) under two different conditions with respect to control was calculated as follows: $\frac{\text { common DEGs under conditionA and conditionB }}{\text { total DEGs under condition B }} * 100$

\subsection{Functional enrichment analysis and annotation}

196 KOBAS (KEGG Orthology-Based Annotation System) standalone tool was used to annotate 197 wheat genes based on blast mapping against rice RefSeq and RAP-DB sequences, e-value $<10^{-}$ 
1985 . For pathway enrichment analysis, the "identify module" was used to shortlist the significantly overrepresented KEGG pathways for the respective deficiency conditions using

200 Fisher's exact test. FDR correction was performed using Benjamini and Hochberg method.

201 Pathway enrichment results were depicted through bubble plots using ggplot2 package [41].

202 The size of the bubbles represents the number of genes altered in the respective pathways, rich

203 factor on $y$-axis was calculated as a ratio of the number of genes altered to the total number of

204 genes in a specific pathway. This means the greater the rich factor, the more intensive the

205 enrichment in a pathway. Also, MapMan [43] was used to map the differentially expressed

206 genes (DEGs) onto metabolic, regulatory and other biological categorical pathways. The

207 mapping file was generated through Mercator [44] using the wheat transcriptome fasta file as

208 an input. In addition, wheat RefSeq v1.1 annotation released by International Wheat Genome

209 Sequencing Consortium (IWGSC) was also used

210 (https://urgi.versailles.inra.fr/download/iwgsc).

\subsection{Identification of cis-regulatory elements}

213 To check the extent of Fe- or P-specific transcriptional regulation in single (Fe or P) and their 214 combined deficiency, sequences for the $1500 \mathrm{bp}$ upstream promoter region for each set of 215 DEGs were downloaded from Ensembl Biomart. The promoter sequences were checked for the 216 presence of 115 frequent cis-regulatory elements (freq-CREs) enriched in clusters for gold 217 standard (GS) Fe responsive genes [14] and phosphate regulation specific CREs using an in218 house perl script (https://github.com/Gazal90/FindMotifs/blob/master/motifs.pl). For validation 219 and comparison, three sets of control groups with 100 promoters each were randomly 220 shortlisted from genes that were not altered in response to Fe deficiency $(-0.5>\log 2 \mathrm{FC}<0.5)$.

\subsection{Gas chromatography-mass spectrometry metabolite profiling}

223 Extraction of total metabolites was performed similarly as previously described [45]. Wheat 224 roots subjected to $+\mathrm{Fe}+\mathrm{P},+\mathrm{Fe}-\mathrm{P},-\mathrm{P}+\mathrm{Fe}$ and $-\mathrm{Fe}-\mathrm{P}$ were sampled at 20 days after deficiency 225 in a triplicate manner and processed for metabolite extraction. The derivatized metabolites 226 were analyzed with a GC instrument (Agilent technologies 7890, USA) coupled with mass 227 spectrometry. The measurement from an injection volume of $1 \mu \mathrm{l}$ was taken in the split-less 228 mode in DB-5 column $(30 \mathrm{~m} \times 0.25 \mathrm{~mm}, 0.25 \mu \mathrm{m}$ film thickness, Agilent $)$ using helium as 229 carrier gas. For analysis, qualitative analysis of chromatograms was performed in MassHunter 230 Qualitative analysis Sp1 workstation (Agilent, USA). Identification and annotation of each 231 compound was supervised manually using AMDIS software and NIST08 database 
232 (http://www.nist.gov/srd/mslist.html). Values were normalized to sample weight and internal

233 control (sorbitol). Statistical analysis was performed as described earlier [46]. $\log _{2}$ ratios of

234 metabolite abundances in tested conditions were plotted against control conditions $(+\mathrm{Fe}+\mathrm{P})$.

235 Delta method approximation was used to calculate standard errors (se) between test (T) and

236 control $(\mathrm{C})$ conditions, se log-ratio $=1 / \ln 2 \sqrt{ }\left[\left(\mathrm{SE}_{\mathrm{T}} / \mathrm{T}\right)^{2}+\left(\mathrm{SE}_{\mathrm{C}} / \mathrm{C}\right)^{2}\right]$, where $\mathrm{SE}_{\mathrm{T}}$ and $\mathrm{SE}_{\mathrm{C}}$ are

237 standard errors of average test and control metabolite abundances. For PCA and hierarchical

238 clustering analysis, the clustv is (https://biit.cs.ut.ee/clustvis/) online program package with

239 Euclidean distance as the similarity measure with complete linkage was used. A tab-delimited

240 file of annotated metabolites with their corresponding log-transformed concentration values

241 was used as input.

242

\subsection{Quantitative real time-PCR analysis}

244 Total RNA was isolated from the roots of the 20 DAT seedlings. A total of two $\mu \mathrm{g}$ of total 245 RNA was used to prepare cDNA by using SuperScript III First-Strand Synthesis System 246 (Invitrogen, USA). Samples were pre-treated with TURBO DNA-free kit to remove genomic 247 contamination (Ambion, TX, USA). To perform quantitative RT-PCR (qRT-PCR) 248 amplification was performed using conserved gene-specific primers capable of amplifying all 249 the homoeologs (Table S1) along with internal control ARF (ADP-Ribosylation Factor) to 250 normalize the expression data for each gene by using the $\mathrm{Ct}$ method $\left[2^{(-\Delta \Delta \mathrm{Ct})}\right]$ in the $\mathrm{CFX} 96^{\mathrm{TM}}$ 251 Real-Time PCR System (BioRadInc, USA). Three independent replicates with two-three 252 technical replicates were performed for each sample [47]. Fe mobilization assay

256 Different metal analysis was performed using Inductive Coupled Plasma-Mass Spectrometry 257 (ICP-MS, Agilent, USA). Metal analysis was performed as described previously [48,49]. 258 Briefly, the mature seeds were grounded to a fine powder and subsequently subjected to the 259 microwave-digested with $\mathrm{HNO}_{3}$ protocol (SuraPure ${ }^{\mathrm{TM}}$, Merck, USA). Respective metal 260 standards were also prepared for analysis. The total chlorophyll content was expressed in terms 261 of SPAD value. This was determined on the fully expanded youngest leaves (3-4 spots per leaf) 262 of seedlings using a portable chlorophyll meter (Konica Minolta SPAD-502, Japan). Eight to 263 ten seedlings were used for these measurements for each treatment. Experiments were repeated 264 thrice with similar observations. Three independent replicates were performed for each 20 265 DAT sample. Pi concentration in wheat roots was measured by the molybdate-blue 
266 colorimetric method with a minimum of three biological replicates (containing $\mathrm{n}=8$ ) [50]. For

267 Perl staining, wheat roots were incubated with Perl's Prussian blue (PPB) method consisting of 268 equal amounts of premixed solution of $4 \%(\mathrm{v} / \mathrm{v}) \mathrm{HCL}$ and $4 \%(\mathrm{w} / \mathrm{v}) \mathrm{K}_{4} \mathrm{Fe}(\mathrm{CN})_{6} \cdot 3 \mathrm{H}_{2} \mathrm{O}$. Roots 269 of eight to ten wheat seedlings from each experiment were taken and incubated in the mixture 270 for 30 mins. Blue colour Fe-plaques were observed for the presence of Fe on the wheat roots 271 seedlings, and representative images (five seedlings per treatment) were taken for respective 272 treatments. To estimate the Fe remobilization ability of these roots, assays was done in the 273 aerobic condition as described earlier in detail [12,51]. Based on these mobilization assays, Fe274 solubilizing capacity was measured. Twenty-five wheat seedlings from each treatment were 275 used for release in $60 \mathrm{ml}$ of deionised water in the presence of Micropur (Katadyn, 276 Switzerland). The final concentration of the released ferrous ion was estimated by measuring OD at $562 \mathrm{~nm}$.

\subsection{Statistical data analysis and data availability}

280 To identify significant differentially expressed genes, a cut-off criterion of $\log 2 \mathrm{FC}>1$ in 281 either direction, with an adjusted p-value (padj) of less than 0.05 was set. The padj values were 282 obtained by using the Benjamini and Hochberg approach for controlling the false discovery

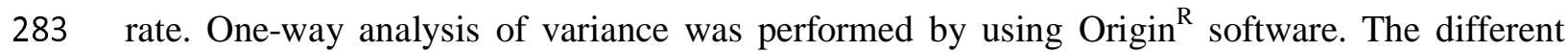
284 letters indicate significant differences of means, and the bars indicate standard deviation (SD). 285 The RNAseq data generated during this study have been deposited under the NCBI SRA database BioProjectID PRJNA667481 and PRJNA529036.

\section{RESULTS}

\subsection{Phenotypic characterization of Fe- and P-deficient wheat}

290 We compared wheat growth under four given conditions: nutrient-sufficient $(+\mathrm{Fe}+\mathrm{P}$, control), 291 single nutrient deficiency $(-\mathrm{Fe}+\mathrm{P}$ and $+\mathrm{Fe}-\mathrm{P})$, and combined nutrient deficiency $(-\mathrm{Fe}-\mathrm{P})$. In 292 the presence of $\mathrm{P},-\mathrm{Fe}$ plants gradually displayed shorter roots compared to the control plants and plants grown in $-\mathrm{P}$ and $-\mathrm{Fe}-\mathrm{P}$ conditions (Figure 1A \& B). Post 20 DAT, the SPAD values (young leaves) were also calculated that measure the severity of the nutrient deficiency. The $\mathrm{Fe}+\mathrm{P}$ treated seedlings show the lowest SPAD $\left(13.7 \pm 1.2^{\mathrm{b}}\right)$, suggesting Fe deficiency impact, whereas no marked symptoms were noted for the $+\mathrm{Fe}+\mathrm{P}\left(34.9 \pm 3.7^{\mathrm{a}}\right)$. Seedlings under dual stress i.e. $-\mathrm{Fe}-\mathrm{P}$, also show a reduction in SPAD $\left(18.0 \pm 2.2^{\mathrm{c}}\right)$, whereas P-deficient seedling, $+\mathrm{Fe}-\mathrm{P}$, show $24.3 \pm 2.6^{\mathrm{d}}$ of SPAD value. In addition, the primary root length shows a slight increase during $-\mathrm{P}$ condition. 
300 Interestingly, the $-\mathrm{Fe}-\mathrm{P}$ condition led to the recovery of total primary root elongation,

301

302

303

304

305

306

307

308

309

310

311

312

313

314

315

316

317

318

319

320

321

322

323

324

325

326

327

328

329

330

331

332

333

alleviating the negative effect of Fe deficiency (Figure 1B). A similar trend was also observed for the number and length of the $1^{\text {st }}$ order lateral roots, which shows a significant increase during $-\mathrm{P}$ and $-\mathrm{Fe}-\mathrm{P}$ conditions relative to $-\mathrm{Fe}$ and control plants (Figure $1 \mathrm{C}$ and $\mathrm{D}$ ). Examination of dry biomass of the seedling was assessed post 20 days of deficiency. The seedling biomass was higher in the control condition ( 1.01 grams per seedling) and lowest in $-\mathrm{P}$ and $-\mathrm{Fe}-\mathrm{P}(\sim 0.47$ and 0.49 grams per seedling) compared to $-\mathrm{Fe}$ ( 0.69 grams per seedling) (Figure 1E). Collectively our experiments suggest that $\mathrm{Fe}$ and $\mathrm{P}$ cross-talk could regulate the biomass allocation to roots and shoots, leading to the representative phenotype. This highlights that the deficiency of $\mathrm{P}$ on the wheat seedlings was more significant than those arising from the Fe deficiency.

\subsection{Effect of deficiency conditions on nutrient content}

Rhizospheric deficiency of Fe and P could affect the uptake of the metal ions in plants [52-55]. To check the influence of the single and dual deficiencies of $\mathrm{P}$ and $\mathrm{Fe}$, we measured the concentration of $\mathrm{Pi}$ (inorganic phosphate), $\mathrm{Zn}$ and Manganese (Mn). During both $-\mathrm{P}$ or $-\mathrm{Fe}-\mathrm{P}$ treatments reduced amount of Pi was measured. Interestingly, in 20 DAT roots, Pi content did not change under single $-\mathrm{Fe}+\mathrm{P}$ deficiency (Figure 2A). Alternatively, significant increases in $\mathrm{Fe}$ accumulation occurred in the roots during $-\mathrm{P}$ (Table 1).

On the other hand, wheat roots showed higher $\mathrm{Zn}$ accumulation under -Fe condition (Table 1). In shoots, high Fe was also significantly accumulated in $-\mathrm{P}$ condition relative to control. The higher accumulation of $\mathrm{Zn}$ was seen in shoots under $-\mathrm{Fe}+\mathrm{P}$ and $-\mathrm{Fe}-\mathrm{P}$ conditions, suggesting the $\mathrm{Zn}$ uptake is independent of P level. Interestingly, in shoots levels, Mn was high in all the treatments compared to control. Perl's staining analysis showed no visual presence of $\mathrm{Fe}$ in roots under $-\mathrm{Fe}$ and $-\mathrm{Fe}-\mathrm{P}$ conditions (Figure $2 \mathrm{~B}$ ). However, enhanced Fe-plaque colourization under $-\mathrm{P}$ conditions and mild staining in $+\mathrm{Fe}+\mathrm{P}$ roots was observed (Figure $2 \mathrm{~B}$ ). Our data suggest that the plant roots aggressively take up Fe under -P conditions. A key aspect of Fe uptake in cereals is the release of PS for its remobilization [56]. Our assays for PS estimation revealed a high Fe-solubilizing capacity (42-47 nM) under-Fe conditions (10DAT), while this capacity decreased in $-\mathrm{P}(8-9 \mathrm{nM})$ and the lowest activity was observed in the control roots (2-3 nM; Figure 2C). Interestingly, a fairly detectable level of Fe-solubilization during $-\mathrm{Fe}-\mathrm{P}$ condition was observed (16-18 nM; Figure $2 \mathrm{C}$ ). This data indicates that $\mathrm{P}$ is necessary for wheat roots to respond to Fe deprivation to enhance their solubilization by releasing PS. 


\subsection{Comparative analysis of normalized RNAseq expression}

336 The combined $\mathrm{Fe}$ and $\mathrm{P}$ deficiencies transcriptomic changes remained largely unaddressed in 337 wheat. Therefore, to understand the molecular basis of observed phenotype and the enhanced 338 accumulation of Fe in -P roots, we performed root RNAseq analysis in all the conditions at 20 339 DAT. We generated 240,013,343 quality-filtered reads, with a minimum of $89 \%$ reads having 340 quality score $>=$ Q30 (Table S2), for the differential expression analysis using the Kallisto341 DESeq2 pipeline [37,38]. PCA plots for normalised gene expression counts revealed distinct 342 clusters for different conditions (Figure S1A). Biological replicates for the respective four 343 conditions (Control, $-\mathrm{Fe},-\mathrm{P},-\mathrm{Fe}-\mathrm{P}$ ) clustered together, thus reinforcing the reliability of the 344 overall comparative analysis (Figure S1A and B). Refined analysis of our previous $-\mathrm{Fe}$ 345 transcriptome subsequently identified 2055 up- and 2191 down-regulated genes compared to 346 the control (Figure 3A). In response to -P condition, 2983 and 802 genes were downregulated 347 and upregulated, respectively (Figure 3A, Table S3). Combined -Fe-P stress caused 348 upregulation and downregulation of 1829 genes and 951 genes (Table S3). The Venn diagram 349 revealed those unique or commonly regulated genes by Fe and P (Figure 3B, Table S4 and 350 Table S5). Clustered heatmap analysis of all 4 transcriptomes revealed that the transcriptomes 351 of control and -Fe-P plants were closer and distant from single Fe or P deficiency conditions 352 (Figure S1B). Clustered heatmap analysis of the top 50 upregulated genes under combined stress across all treatments suggested that expression of these genes was similar in -Fe and -

354 Fe-P conditions (Figure 3C, left panel). In contrast, the strongly downregulated genes (right 355 panel) showed similar patterns during -Fe and -P. Our data suggest that wheat roots respond 356 differently and distinctly to the combined deficiency of Fe and P.

\subsection{Conserved features of response to Fe and $P$ deficiency in hexaploid wheat}

359 DEGs were analyzed for -Fe and -P deficiency to confirm the extent of the single deficiency.

360 Earlier molecular signatures for the Fe deficiency response was reported [12]. Experiments for 361 the other two deficiency conditions were also performed during the same time as the $-\mathrm{Fe}$ 362 experiment, although sequenced and analyzed later. Since Fe deficiency response was 363 characterized earlier [12]; we, therefore, analysed the data to identify the transcriptional 364 changes during $-\mathrm{P}$ and $-\mathrm{Fe}-\mathrm{P}$. During our analysis it was observed that under $-\mathrm{P}$, Phosphate 365 Starvation Response (PHR1) targets such as PHO1;H1 (TraesCS7A02G231200, 366 TraesCS7D02G231300), TaIPS1(TraesCS4B02G312200), Myb TF (TraesCS2A02G100600, 367 TraesCS2B02G117800, TraesCS2D02G100100), phosphatase-related genes like PHOSPHATE 
STARVATION INDUCED 2 (PS2) orthologs (TraesCS3B02G322100, TraesCS3D02G287300)

369 and transcripts encoding for multiple SPX containing domain proteins

370 (TraesCSU02G094800,TraesCS7A02G554800, TraesCS7B02G478000,TraesCS7D02G541100 ,TraesCS7A02G376200,TraesCS7B02G277700 and TraesCS7D02G372600) were

372 significantly upregulated (Table S3). This analysis confirmed a typical P deficiency response in

373 wheat roots, as reported earlier [24]. Also, during -P, genes encoding for MADS-box TFs were

374 highly induced (Table S6). We further evaluated phosphate starvation response (PSR)

375 regulation during $\mathrm{Fe}$ and $\mathrm{P}$ cross-talk by analysing the overlapping expression of PSR genes

376 (Figure 4A, TableS6). The percentage of genes overlapped between $-\mathrm{P}$ and $-\mathrm{Fe}-\mathrm{P}$ was very

377 low (15.79\%). A total of 39 genes were commonly upregulated specifically by $-\mathrm{P}$ and $-\mathrm{Fe}-\mathrm{P}$,

378 including important PSR genes like phosphate starvation-induced gene 2 (PS2). Interestingly,

379 genes encoding for glycine-rich cell wall structural proteins were also highly upregulated in

380 both conditions (Table S8). In contrast, 110 genes were commonly downregulated during these

381 two conditions. Genes encoding peroxidases and proteases were notably repressed. There were

382206 genes with contrasting expression in $-\mathrm{P}$ and $-\mathrm{Fe}-\mathrm{P}$. These included genes encoding for

383 several germin-like protein, GDSL esterase, CytP450s, Glutathione S-Transferases, ABC

384 transporters, TaYS1A and TaVTL5 (Table S8).

385 Similarly, the overlapping expression response of transcripts during $-\mathrm{Fe}$ and $-\mathrm{Fe}-\mathrm{P}$ was

386 found to be comparatively higher (24.96\%; Table 3). Categorically, $-\mathrm{Fe}$ and $-\mathrm{Fe}-\mathrm{P}$

387 transcriptome analysis revealed that $83.65 \%$ DEGs from -Fe alone was no longer differentially

388 expressed under the combined -Fe-P treatment (Figure 4B, Table 3). Our analysis suggests

389 that wheat roots could reprogram metabolic pathways in response to multiple nutrient

390 deficiencies. In total, 494 genes were co-regulated irrespective of the presence or absence of $\mathrm{P}$

391 (Table S9). Out of these, 84 genes were observed to be significantly altered in all three

392 deficiency conditions, including a few WRKY TFs and SPX domain-containing transcripts.

393 There were 62 genes downregulated, including transcripts encoding for ABC-G family

394 transporter and TaYSL12 (Table S9). Further, 410 genes were found to be commonly regulated

395 in Fe deficiency and dual deficiency. Those upregulated by $\mathrm{Fe}$ deficiency included

396 nicotianamine synthase genes-NAS, bHLH and WRKY transcription factors, and transporters

397 viz., ZIFL (zinc induced facilitator-like), YSL, NRT1. Genes repressed by Fe deficiency

398 included $A B C-G$ family, peroxidases, arabinogalactan protein-encoding, sulfate transporter,

399 ferritin and loricrin-like genes. In total 200 genes depicted opposite expression patterns,

400 depending on the presence or absence of $\mathrm{P}$. These included genes encoding for no-apical-

401 meristem (NAC)-domain-, cobalt-ion protein-encoding genes, glycosyltransferases and zinc 
402 transporter (Table S9). These genes also had co-suppressed in the -P and -Fe-P conditions but

403 were induced under -Fe compared to the control root. These were MLO-like protein-coding

404 genes involved in plant defence and stress response [56], sulfotransferase gene, genes encoding

405 for lipid transfer protein, and WAT1-related protein. Furthermore, during -Fe or in -Fe-P,

406 multiple genes involved in Fe homeostasis were also induced that suggested presence of $\mathrm{P}$ does

407 not influence the expression of Fe-homeostasis related transcripts. Specifically,

40893 Fe starvation responsive genes (FSR) were analyzed for their expression (Table S7). FSR

409 genes mostly showed downregulation or no change in expression during P deficiency but were

410 upregulated either in $-\mathrm{Fe}+\mathrm{P}$ or $-\mathrm{Fe}-\mathrm{P}$ (Figure $4 \mathrm{C}$ ). These upregulated genes are known to be

411 involved in the biosynthesis of PS via the methionine salvage pathway.

412 Upon comparative analysis for the single deficiencies (+Fe-P dataset compared to -

$413 \mathrm{Fe}+\mathrm{P}$ ), a total of 3213 genes (660 up- and 2613 down-regulated) were differentially expressed

414 (Table S10). Pathway enrichment analysis suggested the high representation for the

415 phenylpropanoid pathway (PPP), carbon metabolism, carbon fixation and photosynthesis and

416 ribosome related components under P deficiency upon comparison to -Fe (Figure 4D). While

417 ribosome related pathway was enriched among upregulated genes, others mentioned metabolic

418 pathways were downregulated. Multiple MADS-box TF were highly enriched in -P in

419 comparison to $-\mathrm{Fe}$. Others highly induced were ribosomal proteins, dirigent protein, Histone

$420 \mathrm{H} 2 \mathrm{~A}$. As expected, genes with significantly high downregulated in -P compared to -Fe include

421 Fe-homeostasis related genes. This suggests the enrichment of distinct genes contributes to a

422 single or combinatorial deficiency.

\subsection{Unique signatures for $-F e-P$ deficiency response}

425 Next, the comparison was drawn to identify the unique features of -Fe-P compared to control as 426 well as single deficiency (-Fe or $-\mathrm{P})$. Genes encoding Glutathione S-transferases, NBS-LRRs, 427 chaperone-related genes, $\mathrm{ABC}$ and ion transporters were also highly expressed in response to $-\mathrm{Fe}-$

428 P. Additionally, three putative nitrate transporters-NRT (TraesCS5A02G388000;

429 TraesCS7A02G428500; TraesCS3B02G285900) and a gene encoding for nitrate reductase were 430 remarkably downregulated. These expression responses marked the characteristic of $-\mathrm{Fe}-\mathrm{P}$ 431 response in wheat roots and the downregulation of stress-responsive genes, including hydrolase 432 and ATP binding proteins (Table S3). Specifically, eight genes encoding for UDP433 glycosyltransferases were induced during -Fe-P (Table S3). A high number of phytohormone434 related genes involved in auxin response and biosynthesis, including PIN and IAA sub-family 435 genes, were significantly expressed in -Fe-P (Figure S2A \& S2B; Table S11). Mapman analysis 
436 also supports the high expression of genes involved in hormone biosynthesis and secondary

437 metabolism genes (Figure S2A \& S3). Multiple TFs encoding genes forAPETALA2/ethylene 438 response element-binding proteins (AP2/EREBPs), bHLH, MYB, WRKY and C2H2 zinc finger 439 show high expression response in both -Fe and -Fe-P (Table S6, Table S3).

440 To provide insight into the distinct molecular changes caused by the additional deficiency 441 of $\mathrm{P}$ in wheat roots, we studied the expression response in -Fe-P compared to -Fe. In total, 5582 442 genes showed an altered expression (3325 up- and 2257 down-regulated) in the dual deficiency 443 condition when compared to the Fe stressed condition (Table S10). Among the DEGs for this 444 analysis, most prominent were nitrate transporters (7up, 13down), GST (86up, 8down), auxin445 related (22up, 20down), ABA-related (8up, 3down), a sulfur deficiency-induced 2 gene, sulfate 446 transporters (6up, 1down), >30 ABC family transporters, ammonium transporters (6up), 447 glycosyltransferases (63up, 23down) and ferritin (3up). Specifically, the transporters highly 448 induced in dual deficiency compared to single Fe deficiency included nitrate and ammonium 449 transporters, ABC transporters, nucleobase ascorbate transporters (NAT). Three homoeologs for 450 the auxin efflux carrier family genes were induced (TraesCS5D02G361600, 451 TraesCS5B02G356700, TraesCS5A02G354300) among other auxin homeostasis genes. Other 452 transporters induced include phosphate transporters (TraesCS3A02G190800, 453 TraesCS5B02G512100, TraesCS5D02G513000, TraesCS4A02G359900, TraesCS5B02G512000), 454 TaYSL12 homeologs, TaZIFL7.1 (TraesCS4D02G125800, TraesCS4B02G131500). As many as 45566 genes/homoeologs from the ABC subfamily were upregulated. While the highly repressed 456 genes include encoding for terpene-synthase family gene, glutamate receptor (was also induced; 2457 fold), and transporters like zinc and nitrate transporters and a VIT homoeolog 458 (TraesCS2B02G455300). Other transcript encoding for the transporters TaYSL9, TaYS1A, TaYSL1, 459 TaYSL2, TaVIT2 (TraesCS5B02G202100) and TaVIT5 (TraesCS2D02G432000, 460 TraesCS2D02G588000), TaZIFL4.2 (TraesCS4A02G187500) were downregulated. Transcript for 461 the glutamate/malate translocator homolog (TraesCS5D02G256100), 24 aquaporin family genes, 462 NAT and phosphate transporters were also downregulated.

463 We noted that as many as 10 NAS transcripts were downregulated in the $-\mathrm{Fe}-\mathrm{P}$ dual 464 starvation compared to -Fe. The comparative analysis across conditions suggests that although 465 NAS genes' expression is high in both $-\mathrm{Fe}$ and $-\mathrm{Fe}-\mathrm{P}$ compared to control, the intensity of 466 induction is much higher in the former case. In addition, 4 NAAT (TraesCS1A02G291200, 467 TraesCS1B02G300600, TraesCS1D02G289800, TraesCS7A02G334900), TaDMAS1-A 468 (TraesCS4A02G074800, TraesCS4D02G232200) were downregulated, while a DMAS-like gene 469 (TraesCS2A02G315600, TraesCS2B02G333900, TraesCS2D02G313700) was upregulated in - 
470 Fe-P when compared to-Fe. AHA (TraesCS7B02G421700) and many IRT transcripts were

471 downregulated, while expression of numerous PEZ genes was also altered. Two genes encoding

472 for $O s H R Z$ orthologs were downregulated (TraesCS1A02G374800, TraesCS1B02G395000,

473 TraesCS1D02G382000, TraesCS3A02G262700, TraesCS3D02G262600).

474 In contrast, gene enrichment analysis of -Fe-P compared to $-\mathrm{P}$ shows differential

475 expression of 9290 genes (6010 up- and 3280 down-regulated; Table S10). A larger dataset

476 was differentially expressed in $-\mathrm{P}$ when compared to -Fe-P. These DEGs show KEGG

477 enrichment for metabolic pathways, including secondary metabolism and ribosome. Fe uptake

478 and PS biosynthesis genes like ZIFL, YSL, NAS, NAAT were highly induced in dual starvation

479 compared to $-\mathrm{P}$, supporting Fe deficiency response during dual deficiency; however, the

480 severity was less compared to $-\mathrm{Fe}$. These analyses suggest that although the $-\mathrm{Fe}-\mathrm{P}$ share few

481 features of single deficiencies yet; multiple distinct molecular rearrangement occurs to support

482 the physiological changes in wheat seedlings.

483

484

\subsection{KEGG pathway enrichment analysis of DEGs and metabolome analysis}

485 Mapman-based analysis suggests genes involved in UDP-glycosyl-transferases and

486 Glutathione-S-transferases (GST-glutathione) related pathways during-Fe-P were more highly

487 expressed when compared to other treatments and controls (Figure S4 and Figure 5A). Overall,

488 our data indicate that auxin biosynthesis genes and secondary metabolism genes for

489 lignification were highly active in the -Fe-P response (Figure S2, S3 and Figure S5) relative to

490 other treatments. To further categorise the DEGs from each nutritional growth condition, we

491 mapped them to the KEGG database and represented the enriched pathways by means of

492 bubble graphs. Our analysis revealed that in response to $\mathrm{P}$ deficiency, genes related to the

493 phenylpropanoid pathway (PPP), photosynthesis, ABC transporters, and genes for nitrogen

494 metabolism were highly enriched (Figure S5). In response to -Fe-P condition, enrichment of

495 genes involved in glutathione metabolism, glycerophospholipid metabolism, starch and sucrose

496 metabolism and galactose metabolism pathways and cysteine and methionine metabolism was

497 observed (Figure 5B). Interestingly, enrichment of cysteine and methionine metabolism genes

498 was also observed in response to $-\mathrm{Fe}+\mathrm{P}$ treatment [12], indicating that the enrichment of these

499 genes is Fe specific and independent of $\mathrm{P}$ status. Next, we analyzed the significantly altered

500 pathways in the dual deficiency ( $-\mathrm{Fe}-\mathrm{P}$ ) compared to $-\mathrm{Fe}$ and $-\mathrm{P}$ datasets to highlight the

501 unique and common pathway elements among these conditions (Figure 5B). KEGG analysis

502 for the enriched pathways in the -Fe-P treatment compared to -Fe indicates that Cysteine and

503 methionine metabolism, Phenylalanine, tyrosine and tryptophan biosynthesis, sulfur 
504 metabolism, flavonoid biosynthesis, Vitamin B6 metabolism, Diterpenoid biosynthesis were

505 highly enriched in -Fe-P treatment compared to-Fe. While upon extracting the pathways

506 specifically enriched in $-\mathrm{Fe}-\mathrm{P}$ relative to-P were for ribosome synthesis, glyoxylate and

507 dicarboxylate metabolism, inositol phosphate metabolism, photosynthesis, porphyrin and

508 chlorophyll metabolism, phosphatidylinositol signalling system, and ABC transporters were

509 highly represented. This suggests a distinct pathway restructuring during the changing regimes

510 of $\mathrm{P}$ and Fe.

511 Next, we studied the role of primary metabolites, using the GC-MS analysis. Our

512 analysis showed significant variation in the accumulation of metabolites during the nutrient

513 deficiency treatments (Figure 6A, Table S12). While suppression of oxalic acid and increase in

514 4-ketoglucose levels was unique for $-\mathrm{P}$ treatment, the increase in fumaric acid and myo-

515 inositol marked specific metabolic change for $-\mathrm{Fe}$ conditions. A contrasting level of serine and

516 succinic acid in $+\mathrm{Fe}-\mathrm{P}$ (low) and $-\mathrm{Fe}+\mathrm{P}$ (high) was found to be normalized in the combined

517 deficiency relative to the control. The $-\mathrm{Fe}-\mathrm{P}$ conditions is characterized by specific metabolic

518 changes marked by a decrease in acetic acid, butanoic acid, valine, threonine and

519 glucofuranoside levels and increased accumulation of $\beta$-amino-isobutyric acid, strearic acid,

520 arabinonic acid and aconitic acid. Nevertheless, few metabolites decreased in both the $-\mathrm{Fe}-\mathrm{P}$

521 and -Fe conditions such as aspartic acid, hexonic acid, glucose cystathione and, alanine. While

522 the acids showed high accumulation in $-\mathrm{Fe}$, they were highly reduced during $-\mathrm{Fe}-\mathrm{P}$. The

523 metabolites that decrease in $-\mathrm{Fe}-\mathrm{P}$ appeared to follow the same trends in $-\mathrm{P}$ conditions,

524 including citric acid and hexapyranose. Finally, sugars, sugar conjugates (i.e., d-ribofuranose,

525 a-d-galactopyranoside, a-d-mannopyranoside), amino acids (i.e., b-aminoisobutyric acid,

526 cystathione and L-alanine), aconitic acid and arabinonic were predominant in $-\mathrm{Fe}-\mathrm{P}$ conditions

527 (Figure 6B). Overall, our analysis linked the accumulation of specific metabolites that were

528 distinct for a particular condition.

\subsection{Enrichment of Fe responsive cis-regulatory elements in DEGs}

531 Fe-responsive cis-regulatory elements were analyzed in the promoter of differentially 532 expressed genes during $-\mathrm{Fe},-\mathrm{P}$, and $-\mathrm{Fe}-\mathrm{P}$ conditions to get insight into transcriptional 533 regulation. Our analysis revealed multiple TFs that are predominantly expressed in the $-\mathrm{Fe}-\mathrm{P}$ 534 condition compared to P deficiency (Table S6, Figure S6). Genes encoding for multiple bHLH, $535 \mathrm{C} 2 \mathrm{H} 2$ and NAC TFs were highly represented in $-\mathrm{Fe}-\mathrm{P}$. Previously, a comprehensive resource 536 of new putative frequent cis-regulatory elements (freq-pCREs), was also identified in the gene 537 clusters responding to Fe deficiency [14,57]. Herein, we checked for the predominance of freq- 
538 pCREsin the gene-promoters that were differentially regulated in response to single (-Fe and -

$539 \mathrm{P})$ or combined -Fe-P deficiencies using in-silico methods. Although, this study was done

540 using the wheat Ensembl (Chinese Spring) database, yet recent genome sequencing of wheat

541 cv. C-306 [35] was used to confirm the promoter survey observation of this study. This

542 homology matches were confirmed by performing the blast analysis of ten randomly selected

543 FSR gene promoter sequences from Chinese Spring that resulted in the $>99 \%$ identity for each

544 of these genes in C-306. Since, the strategy-II mode of Fe and P uptake remains largely

545 conserved among the wheat cultivars, we extended our study to FSR and PSR related genes

546 from the wheat Ensembl database.

547 Further, to optimize and validate our analysis, we used three control sets of genes

548 ( 100) with $\log _{2} \mathrm{FC}$ between -0.5 and 0.5 in $-\mathrm{Fe}$ with respect to control and checked for the 549 occurrence of freq-pCREs in their promoters. Uniform representation of freq-pCREs was 550 detected in triplicates across each set, thus validating our assessment (Table S13). We then 551 tested this module on a subset of FSR genes and PSR genes. Interestingly, when FSR and PSR552 related genes were analyzed, this balance was found to be perturbed. The dominance and 553 biasness of freq-pCREs were observed significantly in Fe deficiency, as represented in Table 4.

554 For example, cis-domains such as GGCATGA, CACGTC, AAAGTA, ACTAGT, CACACG,

555 AATTGC and CGTGCC were present in higher percentages in Fe deficiency responsive genes 556 as compared to $\mathrm{P}$ deficiency. Similarly, cis-elements for phosphate responsive regions such as

557 P1BS (PHR1 binding sequences, GNATATNC) were present at $62 \%$ of the PSR and $12.90 \%$

558 of FSR genes (Table S14). Interestingly, the P1BS motif was present 34.97, 34,61\% and

$55936.91 \%$ in the promoter regions of DEGs in response to $-\mathrm{Fe}+\mathrm{P},+\mathrm{Fe}-\mathrm{P}$ and $-\mathrm{Fe}-\mathrm{P}$,

560 respectively. Our work revealed an overlapping response of DEGs during-Fe-P deficiency as

561 freq-pCREs were highly enriched in Fe deficiency and present in the promoters of P-response 562 related genes.

\section{4. Discussions}

\subsection{Transcriptome profiling uncovers the link between Fe and P interactions}

$566 \mathrm{Fe}$ and $\mathrm{P}$ are essential elements for plants, utilized in nearly every cellular process. However, there 567 is limited understanding of $\mathrm{Fe}$ and $\mathrm{P}$ homeostasis in crops to coordinate the physiological and 568 molecular responses. The current work aimed to fill this knowledge gap by providing insights into 569 the wheat responses to Fe and/or P deficiency stresses that could help cope with varying soil570 environmental conditions. Our data showed that P deficiency compensates for the negative effect 571 of Fe deficiency on wheat growth and development. Our transcriptome analysis suggests the 
572 enriched presence of putative Fe responsive cis-regulatory binding sites. Combining transcriptome

573 and metabolome analysis revealed a specific component underlying the combined Fe and $\mathrm{P}$ 574 deficiency stress response in wheat.

575 The components of the plant response to P starvation, including the PHR1-controlled IPS1-

576 miR399-PHO2 signaling cascade, remains conserved across the plant kingdom, including wheat

$577[24,58]$. In our $-\mathrm{P}$ wheat root transcriptome analysis, the negative regulator, SPX1 orthologs, was

578 upregulated in accordance with earlier studies noted in rice and wheat [24,59].TaIPS1 induction

579 was complemented by $P H O 1$ and multiple $P H T$ genes being downregulated. However,

580 upregulation of $\mathrm{PHO1} ; \mathrm{H1}$ rice orthologs was observed. RNS1 and RNS3were upregulated in earlier

581 P-starvation studies in rice and wheat but downregulated in our case, which could be a potential

582 marker for the late response to P-starvation. Wheat ortholog for AtTIRl (Transport Inhibitor

583 Response 1), an auxin receptor that is involved in specifically lateral root elongation under -P [60]

584 was found to be induced (TraesCS1D02G099900). Other genes like LPR1, LPR2, PDR2, STOP1

585 and $A L M T 1$, which are central to root architectural changes, specifically reduction in primary root

586 growth, in Arabidopsis, showed no altered expression in $-\mathrm{P}$ condition. However, ALMT and

587 STOP1-like genes show altered expression in -Fe conditions irrespective of $\mathrm{P}$ presence (Table

588 S3).Also, SCARECROW (SCR), a TF involved in regulating root patterning and stem cell

589 maintenance under $-\mathrm{P}$ [61] was not differentially expressed under $-\mathrm{P}$, but altered in the $-\mathrm{Fe}$

590 transcriptome (TraesCS4B02G141400, TraesCS7B02G077800), while 2 SCR genes

591 (TraesCS3A02G360300, TraesCS3B02G392600, TraesCS3D02G354100, TraesCS7B02G078300,

592 TraesCS7D02G174100, TraesCS7D02G174300) were upregulated in -Fe-P.

593 To survive in Fe or P-deficient soils, crop plants like rice, maize, and soybeans have

594 adapted multiple strategy responses. However, crop plant responses to co-occurring $\mathrm{Fe}$ and $\mathrm{P}$

595 stresses remained poorly understood. We observed that common genes expressed in response

596 to $-\mathrm{Fe}$ and -Fe-P supports the Strategy-II mode for Fe uptake even during changing regimes of

597 P. For instance, the relatively high release of PS and gene expression patterns of certain 598 specific YSL, metal transporters and a few TFs involved in metal homeostasis either in -Fe or $599-\mathrm{Fe}-\mathrm{P}$ confirms that wheat primarily utilizes Strategy-II mode of Fe uptake route to mobilize 600 Fe under P deficiency (Figure S7) [62]. Overall, relative high gene expression surge for the 601 FSR genes was observed in Fe deficiency responses, compared to -Fe-P. It was interesting to 602 observe the release of PS even during -P, which could be attributed to the expression of 603 multiple wheat TOM genes [63]. Although the expression of wheat TOM genes was lowered 604 during $-\mathrm{P}$ compared to $-\mathrm{Fe}$, yet the PS release during - $\mathrm{P}$ points to some alternate mechanism 605 for Fe mobilization. Interestingly, accumulation and release of PS in barley roots were shown 
606 to be dependent on the P levels [64]. Based on this, we conclude that, under -Fe condition, 607 optimal P is necessary for enhanced PS accumulation and release. Conversely, ABCG 608 transporters have been speculated to release phenolics and flavins in Arabidopsis to mobilize 609 Fe to roots [65]. However, such substrate analysis for wheat ABC transporter for PS secretion 610 ability remains to be tested. Another possibility is that under $-\mathrm{P}$, multiple organics acids 611 (citrate, malate) are known to be accumulated in wheat roots, enhancing the Fe-solubilization 612 [12]. In future, it will be, therefore, interesting to investigate how -P could cause the release of 613 PS during this condition.

Although $-\mathrm{P}$ condition led to the increase in the root Fe, most of the Strategy II and 615 alternate Fe uptake genes like IRT, NRAMP, ABC transporter genes are either unaltered or 616 downregulated. Strategy II genes like TaYS1A and DMA Synthesis genes are downregulated 617 in $-\mathrm{P}$ as observed in rice [52], while these are upregulated in -Fe-P. Interestingly, TaVTL5 was 618 found to be upregulated in $-\mathrm{P}$ and repressed in both $-\mathrm{Fe}$ conditions. This could be to avoid the 619 Fe toxicity due to increased Fe concentration in $-\mathrm{P}$ roots. Genes involved in root to shoot 620 phosphate transfer were induced under -Fe condition, explaining the increased $\mathrm{P}$ concentration 621 in -Fe shoot. IDEF1 regulates -Fe responses in graminaceous plants. Although IDEF1 core-

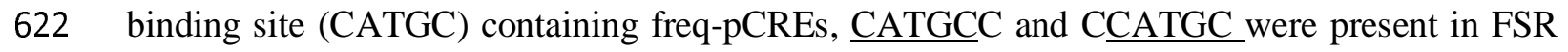
623 gene promoters, yet their occurrence was more predominant in PSR genes. This might suggest 624 a probable IDEF1 role in regulating the increased expression of PSR genes in Fe deficiency. 625 Previously, phylogeny analysis was done across the wheat genomes that suggested close 626 proximity (>97.2) of C-306 with Chinese spring cv [35]. Our extended analysis of the cis627 element in the strategy-II genes in the Chinese spring (Wheat Ensembl) seems to be conserved 628 across the wheat genomes thereby implying the conserved role of $\mathrm{Fe}$ and $\mathrm{P}$ homeostasis across 629 hexaploid wheat genomes. Further, such genetic variations need to be dissected on case-by630 case basis.

Holistic rearrangement of metabolites under Fe, $\mathrm{P}$ and other nutrient deficiencies are necessary to cope with the stress conditions [53]. Our study revealed few specific signatures for the combinatorial deficit (-Fe-P) (Figure 6B). Our data further confirmed that under $\mathrm{P}$ and $\mathrm{Fe}$ 634 deficiencies,plant rootaccumulates organic acids, including malate and citrate, for efficient 635 mobilization of nutrients [66-70]. The accumulation of multiple organic acids is also well 636 reflected in our study during the combined stress condition. Under P deficiency, wheat 637 decreases citrate levels (Table S12 and Figure 6A). Fe deficient wheat roots tend to accumulate 638 high citrate levels with downregulation of citrate synthase transcript (TraesCS7A02G409800, 639 TraesCS7D02G403000). Citrate being a Fe(III) chelator has been reported to play a relevant 
640 role in iron acquisition and xylem Fe transport [71,72]. Overexpression of citrate synthase has

641 been shown to assist plant growth during-P by increasing citrate exudation [73]. Our

642 transcriptome changes support these metabolic changes. Therefore, it could be speculated that

643 the release of the citrate under -P could support efficient mobilization of Fe. Lastly,

644 accumulation of other metabolites, including sugars, sugar conjugates, organic acids, amino

645 acids, fatty acids and polyols, was also observed. Earlier, similar observations for accumulating

646 these metabolites were reported in barley and wheat [74,75]. Altogether, our metabolome

647 analysis suggests strategic rearrangement in wheat roots to ensure $\mathrm{P}$ availability and $\mathrm{Fe}$

648 mobilization. Such cross-talk between $\mathrm{P}$ and Fe to regulate Fe uptake and transport has also

649 been reported in dicots, such as Arabidopsis. For instance, P deficiency was shown to induce

650 Fe homeostasis-related genes like AtFRO2, AtIRT1 and ferritin genes (AtFer1) [18,76,77].

651 Likewise, Fe deficiency can induce the expression of a subset of genes involved in the $\mathrm{P}$

652 acquisition genes [43,78]. These data, along with our observations, points to the unique

653 perspective of plant $\mathrm{P}$ and $\mathrm{Fe}$ interactions.

\subsection{Core components of dual deficiency response}

656 Identifying the specific signatures for the combined deficiency of -Fe and $-\mathrm{P}$ will provide an 657 important link for their homeostatic interactions. This study led to the identification of 658 particular signatures at the transcript and metabolome levels. In plants, the PPP is the primary 659 source of numerous phenylalanine derivatives involved in multiple developments and 660 physiological processes, including lignin biosynthesis and cell wall development $[79,80]$. The 661 role of glycosyltransferases has been demonstrated to control the phenylpropanoid pathway 662 genes [81] efficiently. The high expression of UGT transcripts during -Fe-P suggests 663 reorganization of metabolic pathways that resulted in the defining of molecular signatures. Our 664 MapMan enrichment analysis supports the high expression of genes especially encoding for 665 simple phenols, lignin biosynthesis, isoflavonoids and carotenoids (Figure S5). The high cell 666 wall-related activity in wheat roots could be correlated with enhanced root biomass allocation 667 (Figure 1E). Previously it was observed that lignin biosynthesis could be linked to excess Fe668 related responses to provide tolerance in rice [81]. The affirmative role of lignification and the 669 cytochrome P450 in wheat needs functional attention to address their roles under combined 670 deficiencies.

671 KEGG enrichment analysis reinforced our finding that genes encoding for glutathione 672 metabolism were significantly enriched during -Fe-P treatment. Levels of Glutathione and its 673 metabolism have been correlated with the tolerance for $-\mathrm{Fe}[12,82,83]$. The role of glutathione 
674 under metal stress is well documented [84,85]. In our study, the role of glutathione is reflected

675 by the accumulation of its precursor cystathionine under -Fe as well as in -Fe-P (Figure 6).

676 This suggests that glutathione expression is proportional to the Fe stress in roots. Therefore,

677 one could postulate that, high expression of GST coupled with the glutathione accumulation

678 could be one of the hallmarks Fe deficiency 'gateway modules' that prevent roots against

679 oxidative damage. Other components, such as nitric oxide-mediated iron uptake response, are

680 controlled by glutathione supply [85]. The robust expression of glutathione-related genes in -

$681 \mathrm{Fe}-\mathrm{P}$ condition suggests that roots undergo the redox process required for survival.

682 Accumulation of glycine and serine has been implicated to negatively affect root length and

683 nitrate uptake in Brassica campestris [86].Our data coupled with the previous studies indicated

684 that contrasting glycine and serine accumulation levels in $-\mathrm{Fe}$ conditions could be accounted

685 for short root development [12]. Glycine can induce ethylene-guided inhibition of root

686 elongation, or it could be converted into aminobutyric acid moieties during stress [86,87].

687 The growth during Fe deficiency is in contrast to the decreased total biomass under $\mathrm{P}$ 688 deficiency, and this effect was also reflected in the combined deficiency, i.e., Fe-P. However, 689 this phenomenon was different in the Arabidopsis, where the primary roots were shorter under $690-\mathrm{P}$ and recovered by $-\mathrm{P}-\mathrm{Fe}$ [88]. This indicates that dicots and monocots have evolved distinct 691 genetic programs to respond to single or combined nutrient stress. In contrast, Arabidopsis 692 roots show a reduction in the primary root length in $+\mathrm{Fe}-\mathrm{P}$ [89], whereas in wheat, the effect is reversed with enhanced root growth in $-\mathrm{P}$. Thus, based on our analysis, P-deficient wheat roots could enhance nutrient ( $\mathrm{Fe}, \mathrm{Zn}$ and $\mathrm{Mn}$ ) accumulation, reprogram primary metabolism (oxalate and citrate) and affect the combination of PSR and FSR responses including those involved in auxin homeostasis irrespective of the plant species [30,89].

Plants respond to nutrient stress by shuffling the biomass allocation [90]. It was also reported that due to nutrient stress, levels of sugars/carbohydrates might be perturbed. In this study, the root to shoot biomass allocation was perturbed during the single and combined stress suggesting a conserved mechanism among the plants. Our GC-MS data suggests increasing levels of different sugars (Figure S8) in -Fe condition compared to other stresses. This indicates an increase in the carbohydrate metabolism-related activities to enhancing the biomass allocation in shoots. On similar lines, sucrose accumulates in Arabidopsis roots under

$704-F e$ condition and promotes auxin signalling [91]. These observations in Arabidopsis and 705 wheat are consistent to account for the changes in biomass allocation in stress conditions. The 706 deficiency of individual nutrients like Fe or P affects wheat and other crops for the overall 707 physiological growth and development; and yield components [92,93]. In wheat, we observed 
708 short root under -Fe condition, the rescue of root phenotype by simultaneous -Fe-P stress due

709 to changes in biomass allocation. The enhanced GST dependent auxin activity could explain

710 this compensation effect that influences the number of lateral roots and root adaptation for the

711 combined deprivation stress. GST-mediated regulation of auxin pathway for root architecture

712 re-arrangement has been previously reported in plants [94].

\section{5. Conclusions}

715 Our work highlights the molecular and biochemical changes that are responsible for 716 readjustments for the dual deficiency conditions. Based on the observation, we propose a 717 model for the interaction of $\mathrm{Fe}$ and $\mathrm{P}$ at the rhizospheric level (Figure S9). The effect of $\mathrm{P}$ and 718 Fe deficiency although distinct could provide an interplay between FSR and PSR genes. Early 719 studies in Arabidopsis suggested a working model for the root growth in P deficiency stress 720 contrasts with those observed in rice and wheat despite a consistent accumulation of Fe under $\mathrm{P}$ 721 limitation. In Arabidopsis, the overaccumulation of $\mathrm{Fe}$ in $-\mathrm{P}$ is considered the leading cause of 722 the inhibition of root growth [31]. But in wheat, we showed that the overaccumulation does 723 not inhibit root growth in $-\mathrm{P}$ conditions. We propose that the overaccumulation of $\mathrm{Fe}$ in roots 724 of P-deficient wheat could be accounted for by the persistent release of PS and solubilization 725 by organic acids in the rhizosphere. Our work opens new research avenues to uncover the 726 molecular basis of $\mathrm{P}$ and Fe signalling cross-talk in plants. It will help design strategies to develop wheat cultivars with better Fe and P use efficiency and deficiency tolerance.

\section{Acknowledgements}

730 The authors thank Executive Director, NABI, for facilities and support. This work was funded 731 by the NABI-CORE grant to AKP. GK and VS acknowledge NABI-SRF Fellowships. 732 Technical help from Jagdeep Singh for the GC-MS analysis is highly appreciated. DBT733 eLibrary Consortium (DeLCON) is acknowledged for providing timely support and access to 734 e-resources for this work. We appreciate editing for the English language by Dr Mandy 735 Kendrick, Missouri State University, USA. The wheat genome resources developed by 736 International Wheat Genome Sequencing Consortium are highly appreciated.

739 The authors have declared no conflict of interest.

\section{Author Contributions}


742 Conceptualization, AKP and HR; methodology, GK, VS, VM, DS and PK; formal analysis,

743 GK, AKP, VS, SM and VM; investigation, GK, VS and AK; resources, JS, HR; data curation,

744 GK and VS; writing-original draft preparation, AKP, VS and GK; writing-review and

745 editing, AKP, VM, PK, and GK; supervision, AKP, JS SM, HR; project administration, AKP;

746 funding acquisition, AKP. All authors have read and agreed to the published version of the

747 manuscript.

748

749

\section{REFRENCES}

750 [1] H. Marschner, 9 - Functions of Mineral Nutrients: Micronutrients, in: H.B.T.-M.N. of

751

752

753

754

755

756

757

758

759

760

761

762

763

764

765

766

767

768

769

770

771

772

773

774

775

776

777

778

779

780

781

782

783

784

785

786

787

H.P. (Second E. Marschner (Ed.), Academic Press, London, 1995: pp. 313-404. https://doi.org/https://doi.org/10.1016/B978-012473542-2/50011-0.

[2] J.F. Ma, H.-Q. Ling, Iron for plants and humans, Plant Soil. 325 (2009) 1-3. https://doi.org/10.1007/s11104-009-0203-y.

[3] J. Abadia, S. Vazquez, R. Rellan-Alvarez, H. El-Jendoubi, A. Abadia, A. AlvarezFernandez, A.F. Lopez-Millan, Towards a knowledge-based correction of iron chlorosis., Plant Physiol. Biochem. PPB. 49 (2011) 471-482. https://doi.org/10.1016/j.plaphy.2011.01.026.

[4] T. Kobayashi, N.K. Nishizawa, Iron uptake, translocation, and regulation in higher plants., Annu. Rev. Plant Biol. 63 (2012) 131-152. https://doi.org/10.1146/annurevarplant-042811-105522.

[5] G. Vert, N. Grotz, F. Dédaldéchamp, F. Gaymard, M. Lou Guerinot, J.-F. Briat, C. Curie, IRT1, an Arabidopsis Transporter Essential for Iron Uptake from the Soil and for Plant Growth, Plant Cell. 14 (2002) 1223 LP - 1233. https://doi.org/10.1105/tpc.001388.

[6] D. Eide, M. Broderius, J. Fett, M. Lou Guerinot, A novel iron-regulated metal transporter from plants identified by functional expression in yeast, Proc. Natl. Acad. Sci. U. S. A. 93 (1996) 5624-5628. https://doi.org/10.1073/pnas.93.11.5624.

[7] C. Curie, Z. Panaviene, C. Loulergue, S.L. Dellaporta, J.-F. Briat, E.L. Walker, Maize yellow stripe 1 encodes a membrane protein directly involved in Fe(III) uptake, Nature. 409 (2001) 346-349. https://doi.org/10.1038/35053080.

[8] Y. Murata, J.F. Ma, N. Yamaji, D. Ueno, K. Nomoto, T. Iwashita, A specific transporter for iron(III)-phytosiderophore in barley roots, Plant J. 46 (2006) 563-572. https://doi.org/10.1111/j.1365-313X.2006.02714.X.

[9] H. Inoue, T. Kobayashi, T. Nozoye, M. Takahashi, Y. Kakei, K. Suzuki, M. Nakazono, H. Nakanishi, S. Mori, N.K. Nishizawa, Rice Os YSL15 is an iron-regulated iron(III)deoxymugineic acid transporter expressed in the roots and is essential for iron uptake in early growth of the seedlings., J. Biol. Chem. 284 (2009) 3470-3479. https://doi.org/10.1074/jbc.M806042200.

[10] S. Lee, J.C. Chiecko, S.A. Kim, E.L. Walker, Y. Lee, M. Lou Guerinot, G. An, Disruption of \&lt;em\&gt; Os YSL15\&lt;/em\&gt; Leads to Iron Inefficiency in Rice Plants, Plant Physiol. 150 (2009) 786 LP - 800. https://doi.org/10.1104/pp.109.135418.

[11] T. Nozoye, S. Nagasaka, T. Kobayashi, M. Takahashi, Y. Sato, Y. Sato, N. Uozumi, H. Nakanishi, N.K. Nishizawa, Phytosiderophore efflux transporters are crucial for iron acquisition in graminaceous plants, J. Biol. Chem. 286 (2011) 5446-5454. https://doi.org/10.1074/jbc.M110.180026.

[12] G. Kaur, V. Shukla, A. Kumar, M. Kaur, P. Goel, P. Singh, A. Shukla, V. Meena, J. Kaur, J. Singh, S. Mantri, H. Rouached, A.K. Pandey, Integrative analysis of hexaploid 
wheat roots identifies signature components during iron starvation, J. Exp. Bot. 70 (2019) 6141-6161. https://doi.org/10.1093/jxb/erz358.

[13] E.P. Colangelo, M. Lou Guerinot, The Essential Basic Helix-Loop-Helix Protein FIT1 Is Required for the Iron Deficiency Response, PLANT CELL ONLINE. 16 (2004) 34003412. https://doi.org/10.1105/tpc.104.024315.

[14] B. Schwarz, C.B. Azodi, S.-H. Shiu, P. Bauer, Putative cis-Regulatory Elements Predict Iron Deficiency Responses in Arabidopsis Roots, Plant Physiol. 182 (2020) 1420 LP 1439. https://doi.org/10.1104/pp.19.00760.

[15] Y.X. Yuan, J. Zhang, D.W. Wang, H.Q. Ling, AtbHLH29 of Arabidopsis thaliana is a functional ortholog of tomato FER involved in controlling iron acquisition in strategy I plants, Cell Res. 15 (2005) 613-621. https://doi.org/10.1038/sj.cr.7290331.

[16] Y. Ogo, R. Nakanishi Itai, H. Nakanishi, T. Kobayashi, M. Takahashi, S. Mori, N.K. Nishizawa, The rice bHLH protein OsIRO2 is an essential regulator of the genes involved in Fe uptake under Fe-deficient conditions, Plant J. 51 (2007) 366-377. https://doi.org/10.1111/j.1365-313X.2007.03149.x.

[17] Y. Ogo, R.N. Itai, H. Nakanishi, H. Inoue, T. Kobayashi, M. Suzuki, M. Takahashi, S. Mori, N.K. Nishizawa, Isolation and characterization of IRO2, a novel iron-regulated bHLH transcription factor in graminaceous plants., J. Exp. Bot. 57 (2006) 2867-2878. https://doi.org/10.1093/jxb/erl054.

[18] J. Misson, K.G. Raghothama, A. Jain, J. Jouhet, M.A. Block, R. Bligny, P. Ortet, A. Creff, S. Somerville, N. Rolland, P. Doumas, P. Nacry, L. Herrerra-Estrella, L. Nussaume, M.-C. Thibaud, A genome-wide transcriptional analysis using Arabidopsis thaliana Affymetrix gene chips determined plant responses to phosphate deprivation., Proc. Natl. Acad. Sci. U. S. A. 102 (2005) 11934-11939. https://doi.org/10.1073/pnas.0505266102.

[19] N. Bouain, P. Doumas, H. Rouached, Recent Advances in Understanding the Molecular Mechanisms Regulating the Root System Response to Phosphate Deficiency in Arabidopsis, Curr. Genomics. 17 (2016) 304-308. https://doi.org/10.2174/1389202917666160331201812.

[20] A.R. Narayanan K., Effect of phosphorus deficiency on the form of plant root system, Slough, UK Commonw. Agric. Bur. C1982. (1982) 412-417.

[21] A. Mollier, S. Pellerin, Maize root system growth and development as influenced by phosphorus deficiency, J. Exp. Bot. 50 (1999) 487-497. https://doi.org/10.1093/jxb/50.333.487.

[22] A. Shimizu, S. Yanagihara, S. Kawasaki, H. Ikehashi, Phosphorus deficiency-induced root elongation and its QTL in rice (Oryza sativa L.), Theor. Appl. Genet. 109 (2004) 1361-1368. https://doi.org/10.1007/s00122-004-1751-4.

[23] H. Cai, W. Xie, T. Zhu, X. Lian, Transcriptome response to phosphorus starvation in rice, Acta Physiol. Plant. 34 (2012) 327-341. https://doi.org/10.1007/s11738-011-08327.

[24] Y. Oono, F. Kobayashi, Y. Kawahara, T. Yazawa, H. Handa, T. Itoh, T. Matsumoto, Characterisation of the wheat (Triticum aestivum L.) transcriptome by de novo assembly for the discovery of phosphate starvation-responsive genes: gene expression in Pistressed wheat., BMC Genomics. 14 (2013) 77. https://doi.org/10.1186/1471-2164-1477.

[25] D. Secco, M. Jabnoune, H. Walker, H. Shou, P. Wu, Y. Poirier, J. Whelan, Spatiotemporal transcript profiling of rice roots and shoots in response to phosphate starvation and recovery, Plant Cell. 25 (2013) 4285-4304. https://doi.org/10.1105/tpc.113.117325.

[26] C.C. Dalton, K. Iqbal, D.A. Turner, Iron phosphate precipitation in Murashige and Skoog media, Physiol. Plant. 57 (1983) 472-476. https://doi.org/10.1111/j.1399- 


\begin{tabular}{|c|c|c|}
\hline 838 & & \\
\hline 839 & [27] & Chutia, S. Abel, J. Ziegler, Iron and Phosphate Deficiency Regulators Concertedly \\
\hline 40 & & Control Coumarin Profiles in Arabidopsis thaliana Roots During Iron, Phosphate, and \\
\hline 341 & & Combined Deficiencies , Front. Plant Sci. . 10 (2019) 113. \\
\hline 842 & & https://www.frontiersin.org/article/10.3389/fpls.2019.00113. \\
\hline 843 & [28] & X. Xie, W. Hu, X. Fan, H. Chen, M. Tang, Interactions Between Phosphorus, Zinc, and \\
\hline 44 & & Iron Homeostasis in Nonmycorrhizal and Mycorrhizal Plants, Front. Plant Sci. 10 (2019) \\
\hline 845 & & 1172. https://doi.org/10.3389/fpls.2019.01172. \\
\hline 346 & [29] & J. Hirsch, E. Marin, M. Floriani, S. Chiarenza, P. Richaud, L. Nussaume, M.C. Thibaud, \\
\hline 347 & & Phosphate deficiency promotes modification of iron distribution in Arabidopsis plants., \\
\hline 48 & & Biochimie. 88 (2006) 1767-1771. https://doi.org/10.1016/j.biochi.2006.05.007. \\
\hline 849 & [30] & J.T. Ward, B. Lahner, E. Yakubova, D.E. Salt, K.G. Raghothama, The effect of iron on \\
\hline 850 & & the primary root elongation of Arabidopsis during phosphate deficiency, Plant Physiol. \\
\hline 851 & & 147 (2008) 1181-1191. https://doi.org/10.1104/pp.108.118562. \\
\hline 852 & [31] & J.T. Ward, B. Lahner, E. Yakubova, D.E. Salt, K.G. Raghothama, The effect of iron on \\
\hline 353 & & the primary root elongation of Arabidopsis during phosphate deficiency, Plant Physiol. \\
\hline 854 & & 147 (2008) 1181-1191. https://doi.org/10.1104/pp.108.118562. \\
\hline 855 & [32] & J. WASAKI, R. YONETANI, S. KURODA, T. SHINANO, J. YAZAKI, F. FUJII, K. \\
\hline 856 & & SHIMBO, K. YAMAMOTO, K. SAKATA, T. SASAKI, N. KISHIMOTO, S. \\
\hline 857 & & KIKUCHI, M. YAMAGISHI, M. OSAKI, Transcriptomic analysis of metabolic changes \\
\hline 858 & & by phosphorus stress in rice plant roots, Plant. Cell Environ. 26 (2003) $1515-1523$. \\
\hline 859 & & https://doi.org/https://doi.org/10.1046/j.1365-3040.2003.01074.x. \\
\hline 860 & [33] & W. Li, P. Lan, The Understanding of the Plant Iron Deficiency Responses in Strategy I \\
\hline 861 & & Plants and the Role of Ethylene in This Process by Omic Approaches, Front. Plant Sci. 8 \\
\hline 862 & & (2017) 40. https://doi.org/10.3389/fpls.2017.00040. \\
\hline 863 & [34] & H. Rouached, A.B. Arpat, Y. Poirier, Regulation of phosphate starvation responses in \\
\hline 864 & & plants: signaling players and cross-talks., Mol. Plan \\
\hline 865 & & https://doi.org/10.1093/mp/ssp120. \\
\hline 866 & [35] & A. Mishra, A. Singh, S. Mantri, A.K. Pandey, M. Garg, R. Deshmukh, H. Sonah, P.K. \\
\hline 867 & & Kandoth, T.R. Sharma, J. Roy, Decoding the genome of superior chapatti quality Indian \\
\hline 868 & & wheat variety 'C 306' unravelled novel genomic variants for chapatti and nutrition \\
\hline 869 & & quality related genes, Genomics. 113 (202 \\
\hline 870 & & /https://doi.org \\
\hline 871 & [36] & V. Shukla, M. Kaur, A. Sipla, K.K. Bhati, J. Kaur, Tissue specific transcript profiling of \\
\hline 872 & & \\
\hline 873 & & \\
\hline 874 & [37] & N.L. Bray, H. Pimentel, P. Melsted, L. Pachter, I \\
\hline 875 & & quantification., Nat. Biotechnol. 34 (2016) 525-527. https://doi.org/10.1038/nbt.3519. \\
\hline 876 & [38] & M.I. Love, W. Huber, S. Anders, Moderated estimation of fold change and dispersion \\
\hline 877 & & for RNA-seq data with DESeq2, Genome Biol. 15 (2014) 550. \\
\hline 878 & & \\
\hline 879 & [39] & C. Soneson, M.I. Love, M.D. Robinson, Differential analyses for RNA-seq: transcript- \\
\hline 880 & & \\
\hline 881 & & ttps://doi.org/10.12688/f1000research.7563.2. \\
\hline 882 & [40] & M.E. Ritchie, B. Phipson, D. Wu, Y. Hu, C.W. Law, W. Shi, G.K. Smyth, limma powers \\
\hline 883 & & \\
\hline 884 & & Acids Res. 43 (2015) e47-e47. https://doi.org/10.1093/nar/gkv007. \\
\hline 885 & [41] & H. Wickham, Book review: ggplot2 - Elegant Graphics for Data Analysis (2nd Edition), \\
\hline 886 & & (2017) 2-5. https://doi.org/10.18637/jss.v077.b02. \\
\hline & [42] & Zhu, J.G. Ibrahim, M.I. Love, Heavy-tailed prior distributions for sequence count \\
\hline
\end{tabular}


data: removing the noise and preserving large differences, Bioinformatics. 35 (2018) 2084-2092. https://doi.org/10.1093/bioinformatics/bty895.

[43] O. Thimm, O. Bläsing, Y. Gibon, A. Nagel, S. Meyer, P. Krüger, J. Selbig, L.A. Müller, S.Y. Rhee, M. Stitt, mapman: a user-driven tool to display genomics data sets onto diagrams of metabolic pathways and other biological processes, Plant J. 37 (2004) 914939. https://doi.org/10.1111/j.1365-313X.2004.02016.x.

[44] M. LOHSE, A. NAGEL, T. HERTER, P. MAY, M. SCHRODA, R. ZRENNER, T. TOHGE, A.R. FERNIE, M. STITT, B. USADEL, Mercator: a fast and simple web server for genome scale functional annotation of plant sequence data, Plant. Cell Environ. 37 (2014) 1250-1258. https://doi.org/10.1111/pce.12231.

[45] Y. Wang, E. Lysøe, T. Armarego-Marriott, A. Erban, L. Paruch, A. van Eerde, R. Bock, J. Liu-Clarke, Transcriptome and metabolome analyses provide insights into root and root-released organic anion responses to phosphorus deficiency in oat., J. Exp. Bot. 69 (2018) 3759-3771. https://doi.org/10.1093/jxb/ery176.

[46] S. Quanbeck, L. Brachova, A. Campbell, X. Guan, A. Perera, K. He, S. Rhee, P. Bais, J. Dickerson, P. Dixon, G. Wohlgemuth, O. Fiehn, L. Barkan, B.M. Lange, I. Lee, D. Cortes, C. Salazar, J. Shuman, V. Shulaev, D. Huhman, L. Sumner, M. Roth, R. Welti, H. Ilarslan, E. Wurtele, B. Nikolau, Metabolomics as a Hypothesis-Generating Functional Genomics Tool for the Annotation of Arabidopsis thaliana Genes of "Unknown Function" , Front. Plant Sci. . 3 (2012) 15. https://www.frontiersin.org/article/10.3389/fpls.2012.00015.

[47] K.J. Livak, T.D. Schmittgen, Analysis of relative gene expression data using real-time quantitative PCR and the 2(-Delta Delta C(T)) Method., Methods. 25 (2001) 402-408. https://doi.org/10.1006/meth.2001.1262.

[48] K.K. Bhati, A. Alok, A. Kumar, J. Kaur, S. Tiwari, A.K. Pandey, Silencing of ABCC13 transporter in wheat reveals its involvement in grain development, phytic acid accumulation and lateral root formation., J. Exp. Bot. 67 (2016) 4379-4389. https://doi.org/10.1093/jxb/erw224.

[49] S. Aggarwal, A. Kumar, K.K. Bhati, G. Kaur, V. Shukla, S. Tiwari, A.K. Pandey, RNAi-Mediated Downregulation of Inositol Pentakisphosphate Kinase (IPK1) in Wheat Grains Decreases Phytic Acid Levels and Increases Fe and Zn Accumulation, Front. Plant Sci. 9 (2018) 259. https://doi.org/10.3389/fpls.2018.00259.

[50] P.S. Chen, T.Y. Toribara, H. Warner, Microdetermination of Phosphorus, Anal. Chem. 28 (1956) 1756-1758. https://doi.org/10.1021/ac60119a033.

[51] S.I. Takagi, Naturally occurring iron. Chelating compounds in oat- and rice-rootwashings 1 . activity measurement and preliminary characterization, Soil Sci. Plant Nutr. 22 (1976) 423-433. https://doi.org/10.1080/00380768.1976.10433004.

[52] L. Zheng, F. Huang, R. Narsai, J. Wu, E. Giraud, F. He, L. Cheng, F. Wang, P. Wu, J. Whelan, H. Shou, Physiological and transcriptome analysis of iron and phosphorus interaction in rice seedlings, Plant Physiol. 151 (2009) 262-274. https://doi.org/10.1104/pp.109.141051.

[53] J.F. Briat, C. Dubos, F. Gaymard, Iron nutrition, biomass production, and plant product quality, Trends Plant Sci. 20 (2015) 33-40. https://doi.org/10.1016/j.tplants.2014.07.005.

[54] R. Ghasemi-Fasaei, A. Ronaghi, Interaction of Iron with Copper, Zinc, and Manganese in Wheat as Affected by Iron and Manganese in a Calcareous Soil, J. Plant Nutr. 31 (2008) 839-848. https://doi.org/10.1080/01904160802043148.

[55] M.-R. Martínez-Cuenca, A. Quiñones, D.J. Iglesias, M.Á. Forner-Giner, E. Primo-Millo, F. Legaz, Effects of high levels of zinc and manganese ions on Strategy I responses to iron deficiency in citrus, Plant Soil. 373 (2013) 943-953. 
938

939

940

941

942

943

944

945

946

947

948

949

950

951

952

953

954

955

956

957

958

959

960

961

962

963

964

965

966

967

968

969

970

971

972

973

974

975

976

977

978

979

980

981

982

983

984

985

986

987 http://www.jstor.org/stable/42952533.

[56] V. Römheld, The role of phytosiderophores in acquisition of iron and other micronutrients in graminaceous species: An ecological approach, Plant Soil. 130 (1991) 127-134. https://doi.org/10.1007/BF00011867.

[57] R. Ivanov, T. Brumbarova, P. Bauer, Fitting into the Harsh Reality: Regulation of Irondeficiency Responses in Dicotyledonous Plants, Mol. Plant. 5 (2012) 27-42. https://doi.org/https://doi.org/10.1093/mp/ssr065.

[58] X. Ouyang, X. Hong, X. Zhao, W. Zhang, X. He, W. Ma, W. Teng, Y. Tong, Knock out of the PHOSPHATE 2 Gene TaPHO2-A1 Improves Phosphorus Uptake and Grain Yield under Low Phosphorus Conditions in Common Wheat., Sci. Rep. 6 (2016) 29850. https://doi.org/10.1038/srep29850.

[59] Y. Oono, Y. Kawahara, H. Kanamori, H. Mizuno, H. Yamagata, M. Yamamoto, S. Hosokawa, H. Ikawa, I. Akahane, Z. Zhu, J. Wu, T. Itoh, T. Matsumoto, mRNA-Seq Reveals a Comprehensive Transcriptome Profile of Rice under Phosphate Stress, Rice. 4 (2011) 50-65. https://doi.org/10.1007/s12284-011-9064-0.

[60] C.-A. Pérez-Torres, J. López-Bucio, A. Cruz-Ramírez, E. Ibarra-Laclette, S. Dharmasiri, M. Estelle, L. Herrera-Estrella, Phosphate availability alters lateral root development in Arabidopsis by modulating auxin sensitivity via a mechanism involving the TIR 1 auxin receptor, Plant Cell. 20 (2008) 3258-3272. https://doi.org/10.1105/tpc.108.058719.

[61] C.A. Ticconi, R.D. Lucero, S. Sakhonwasee, A.W. Adamson, A. Creff, L. Nussaume, T. Desnos, S. Abel, ER-resident proteins PDR2 and LPR1 mediate the developmental response of root meristems to phosphate availability, Proc. Natl. Acad. Sci. U. S. A. 106 (2009) 14174-14179. https://doi.org/10.1073/pnas.0901778106.

[62] A. Kumar, G. Kaur, P. Goel, K.K. Bhati, M. Kaur, V. Shukla, A.K. Pandey, Genomewide analysis of oligopeptide transporters and detailed characterization of yellow stripe transporter genes in hexaploid wheat., Funct. Integr. Genomics. 19 (2019) 75-90. https://doi.org/10.1007/s10142-018-0629-5.

[63] S. Sharma, G. Kaur, A. Kumar, V. Meena, J. Kaur, A.K. Pandey, Overlapping transcriptional expression response of wheat zinc-induced facilitator-like transporters emphasize important role during Fe and Zn stress, BMC Mol. Biol. 20 (2019) 22. https://doi.org/10.1186/s12867-019-0139-6.

[64] A. Ladouceur, S. Tozawa, S. Alam, S. Kamei, S. Kawai, Effect of low phosphorus and iron-deficient conditions on phytosiderophore release and mineral nutrition in barley, Soil Sci. Plant Nutr. 52 (2006) 203-210. https://doi.org/10.1111/j.17470765.2006.00022.x.

[65] P. Fourcroy, P. Sisó-Terraza, D. Sudre, M. Savirón, G. Reyt, F. Gaymard, A. Abadía, J. Abadia, A. Álvarez-Fernández, J.-F. Briat, Involvement of the ABCG37 transporter in secretion of scopoletin and derivatives by Arabidopsis roots in response to iron deficiency, New Phytol. 201 (2014) 155-167.

https://doi.org/https://doi.org/10.1111/nph.12471.

[66] A. Kania, N. Langlade, E. Martinoia, G. Neumann, Phosphorus deficiency-induced modifications in citrate catabolism and in cytosolic $\mathrm{pH}$ as related to citrate exudation in cluster roots, Plant Soil. 248 (2003) 117-127. https://doi.org/10.1023/A:1022371115788.

[67] A. Ligaba, H. Shen, K. Shibata, Y. Yamamoto, S. Tanakamaru, H. Matsumoto, The role of phosphorus in aluminium-induced citrate and malate exudation from rape (Brassica napus)., Physiol. Plant. 120 (2004) 575-584. https://doi.org/10.1111/j.00319317.2004.0290.x.

[68] T. Mimmo, D. Del Buono, R. Terzano, N. Tomasi, G. Vigani, C. Crecchio, R. Pinton, G. Zocchi, S. Cesco, Rhizospheric organic compounds in the soil-microorganism-plant 


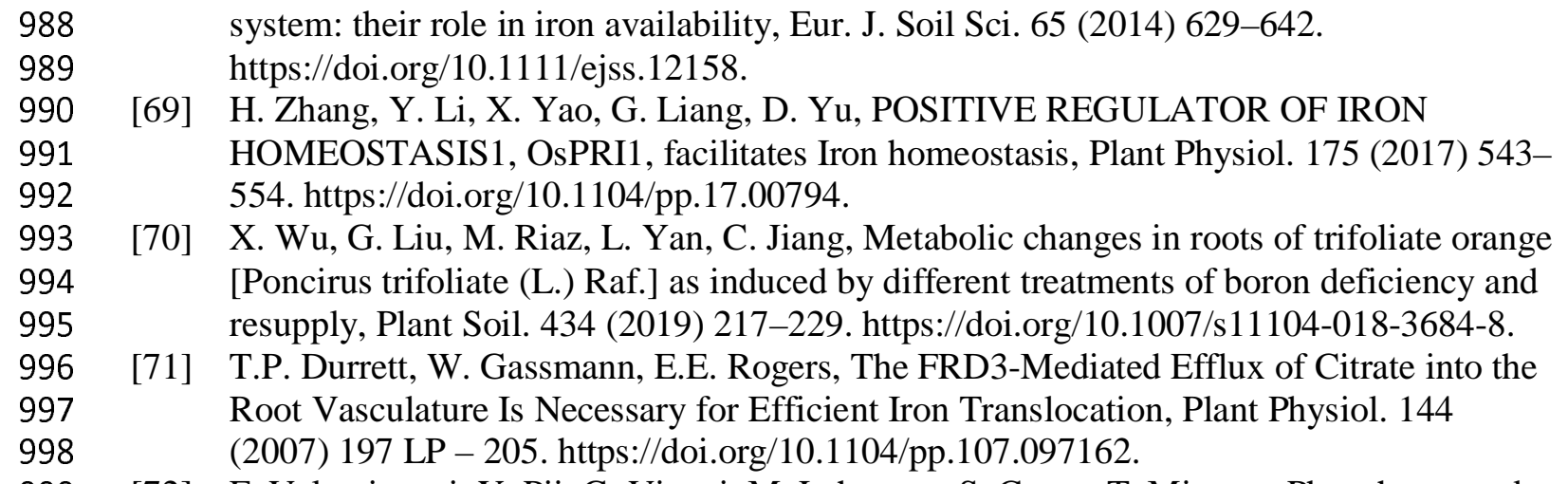

999

1000

1001

1002

1003

1004

1005

1006

1007

1008

1009

1010

1011

1012

1013

1014

1015

1016

1017

1018

1019

1020

1021

1022

1023

1024

1025

1026

1027

1028

1029

1030

1031

1032

1033

1034

1035

1036

1037

[72] F. Valentinuzzi, Y. Pii, G. Vigani, M. Lehmann, S. Cesco, T. Mimmo, Phosphorus and iron deficiencies induce a metabolic reprogramming and affect the exudation traits of the woody plant Fragariaxananassa, J. Exp. Bot. 66 (2015) 6483-6495. https://doi.org/10.1093/jxb/erv364.

[73] V.M. Anoop, U. Basu, M.T. McCammon, L. McAlister-Henn, G.J. Taylor, Modulation of citrate metabolism alters aluminum tolerance in yeast and transgenic canola overexpressing a mitochondrial citrate synthase, Plant Physiol. 132 (2003) 2205-2217. https://doi.org/10.1104/pp.103.023903.

[74] C.Y. Huang, U. Roessner, I. Eickmeier, Y. Genc, D.L. Callahan, N. Shirley, P. Langridge, A. Bacic, Metabolite Profiling Reveals Distinct Changes in Carbon and Nitrogen Metabolism in Phosphate-Deficient Barley Plants (Hordeum vulgare L.), Plant Cell Physiol. 49 (2008) 691-703. https://doi.org/10.1093/pcp/pcn044.

[75] L.J. Palmer, D.A. Dias, B. Boughton, U. Roessner, R.D. Graham, J.R. Stangoulis, Metabolite profiling of wheat (Triticum aestivum L.) phloem exudate, Plant Methods. 10 (2014) 27. https://doi.org/10.1186/1746-4811-10-27.

[76] Y.-H. Wang, D.F. Garvin, L. V Kochian, Rapid induction of regulatory and transporter genes in response to phosphorus, potassium, and iron deficiencies in tomato roots. Evidence for cross talk and root/rhizosphere-mediated signals., Plant Physiol. 130 (2002) 1361-1370. https://doi.org/10.1104/pp.008854.

[77] M. Bournier, N. Tissot, S. Mari, J. Boucherez, E. Lacombe, J.-F. Briat, F. Gaymard, Arabidopsis ferritin 1 (AtFer1) gene regulation by the phosphate starvation response 1 (AtPHR1) transcription factor reveals a direct molecular link between iron and phosphate homeostasis., J. Biol. Chem. 288 (2013) 22670-22680. https://doi.org/10.1074/jbc.M113.482281.

[78] C. Lucena, R. Porras, M.J. García, E. Alcántara, R. Pérez-Vicente, Á.M. Zamarreño, E. Bacaicoa, J.M. García-Mina, A.P. Smith, F.J. Romera, Ethylene and Phloem Signals Are Involved in the Regulation of Responses to Fe and P Deficiencies in Roots of Strategy I Plants , Front. Plant Sci. . 10 (2019) 1237. https://www.frontiersin.org/article/10.3389/fpls.2019.01237.

[79] C.J. Douglas, Phenylpropanoid metabolism and lignin biosynthesis: from weeds to trees, Trends Plant Sci. 1 (1996) 171-178. https://doi.org/https://doi.org/10.1016/13601385(96)10019-4.

[80] W. Boerjan, J. Ralph, M. Baucher, Lignin biosynthesis., Annu. Rev. Plant Biol. 54 (2003) 519-546. https://doi.org/10.1146/annurev.arplant.54.031902.134938.

[81] R.J. Stein, G.L. Duarte, L. Scheunemann, M.G. Spohr, A.T. de Araújo Júnior, F.K. Ricachenevsky, L.M.G. Rosa, N.I.T. Zanchin, R.P. dos Santos, J.P. Fett, Genotype variation in rice (Oryza sativa 1.) tolerance to fe toxicity might be linked to root cell wall lignification, Front. Plant Sci. 10 (2019) 1-20. https://doi.org/10.3389/fpls.2019.00746.

[82] T.B. Zaharieva, J. Abadia, Iron deficiency enhances the levels of ascorbate, glutathione, 
1038

1039

1040

1041

1042

1043

1044

1045

1046

1047

1048

1049

1050

1051

1052

1053

1054

1055

1056

1057

1058

1059

1060

1061

1062

1063

1064

1065

1066

1067

1068

1069

1070

1071

1072

1073

1074

1075

1076

1077

1078

1079

1080

1081

1082

1083

1084

1085

and related enzymes in sugar beet roots., Protoplasma. 221 (2003) 269-275. https://doi.org/10.1007/s00709-002-0051-6.

[83] K. Bashir, S. Nagasaka, R.N. Itai, T. Kobayashi, M. Takahashi, H. Nakanishi, S. Mori, N.K. Nishizawa, Expression and enzyme activity of glutathione reductase is upregulated by Fe-deficiency in graminaceous plants., Plant Mol. Biol. 65 (2007) 277-284. https://doi.org/10.1007/s11103-007-9216-1.

[84] L. Ramírez, C.G. Bartoli, L. Lamattina, Glutathione and ascorbic acid protect Arabidopsis plants against detrimental effects of iron deficiency., J. Exp. Bot. 64 (2013) 3169-3178. https://doi.org/10.1093/jxb/ert153.

[85] V. Shanmugam, Y.-W. Wang, M. Tsednee, K. Karunakaran, K.-C. Yeh, Glutathione plays an essential role in nitric oxide-mediated iron-deficiency signaling and irondeficiency tolerance in Arabidopsis, Plant J. 84 (2015) 464-477. https://doi.org/10.1111/tpj.13011.

[86] R. Han, M. Khalid, J. Juan, D. Huang, Exogenous glycine inhibits root elongation and reduces nitrate-N uptake in pak choi (Brassica campestris ssp. Chinensis L.), PLoS One. 13 (2018) e0204488-e0204488. https://doi.org/10.1371/journal.pone.0204488.

[87] A.U. Igamberdiev, L.A. Kleczkowski, Thermodynamic buffering, stable nonequilibrium and establishment of the computable structure of plant metabolism, Prog. Biophys. Mol. Biol. 146 (2019) 23-36. https://doi.org/https://doi.org/10.1016/j.pbiomolbio.2018.11.005.

[88] N. Bouain, G. Krouk, B. Lacombe, H. Rouached, Getting to the Root of Plant Mineral Nutrition: Combinatorial Nutrient Stresses Reveal Emergent Properties, Trends Plant Sci. 24 (2019) 542-552. https://doi.org/10.1016/j.tplants.2019.03.008.

[89] V. Rai, R. Sanagala, B. Sinilal, S. Yadav, A.K. Sarkar, P.K. Dantu, A. Jain, Iron Availability Affects Phosphate Deficiency-Mediated Responses, and Evidence of CrossTalk with Auxin and Zinc in Arabidopsis, Plant Cell Physiol. 56 (2015) 1107-1123. https://doi.org/10.1093/pcp/pcv035.

[90] C. Hermans, J.P. Hammond, P.J. White, N. Verbruggen, How do plants respond to nutrient shortage by biomass allocation?, Trends Plant Sci. 11 (2006) 610-617. https://doi.org/10.1016/j.tplants.2006.10.007.

[91] X.Y. Lin, Y.Q. Ye, S.K. Fan, C.W. Jin, S.J. Zheng, Increased Sucrose Accumulation Regulates Iron-Deficiency Responses by Promoting Auxin Signaling in Arabidopsis Plants, Plant Physiol. 170 (2016) 907-920. https://doi.org/10.1104/pp.15.01598.

[92] R.B. Clark, E.P. Williams, W.M. Ross, G.M. Herron, M.D. Witt, Effect of iron deficiency chlorosis on growth and yield component traits of sorghum, J. Plant Nutr. 11 (1988) 747-754. https://doi.org/10.1080/01904168809363839.

[93] A. Carstensen, A. Herdean, S.B. Schmidt, A. Sharma, C. Spetea, M. Pribil, S. Husted, The Impacts of Phosphorus Deficiency on the Photosynthetic Electron Transport Chain, Plant Physiol. 177 (2018) 271 LP - 284. https://doi.org/10.1104/pp.17.01624.

[94] J.A. Trujillo-Hernandez, L. Bariat, T.A. Enders, L.C. Strader, J.-P. Reichheld, C. Belin, A glutathione-dependent control of the indole butyric acid pathway supports Arabidopsis root system adaptation to phosphate deprivation, J. Exp. Bot. 71 (2020) 4843-4857. https://doi.org/10.1093/jxb/eraa195.

Table 1: Metal concentration in roots and shoots of wheat seedling subjected to -Fe, -P and -Fe-P stress. Different letters indicate significant changes within the treatments. One-way Annova and Duncan test $(\mathrm{p}>0.05)$ was performed for each within the treatments. 


\begin{tabular}{|l|l|l|l|l|l|l|}
\hline & \multicolumn{7}{|l|}{ Root } & Shoot & \\
\hline Treatment & Fe & Zn & Mn & Fe & Zn & Mn \\
\hline$(+\mathrm{Fe}+\mathrm{P})$ & $160.91 \pm 4.66^{\mathrm{a}}$ & $27.1 \pm 0.88^{\mathrm{a}}$ & $59.53 \pm 2.87^{\mathrm{a}}$ & $86.87 \pm 4.19^{\mathrm{a}}$ & $24.43 \pm 1.76^{\mathrm{a}}$ & $21.52 \pm 0.94^{\mathrm{a}}$ \\
\hline$(+\mathrm{Fe}-\mathrm{P})$ & $192.8 \pm 12.73^{\mathrm{b}}$ & $21.73 \pm 1.42^{\mathrm{b}}$ & $53.17 \pm 3.77^{\mathrm{b}}$ & $106.68 \pm 6.16^{\mathrm{b}}$ & $21.54 \pm 0.94^{\mathrm{a}}$ & $33.88 \pm 1.06^{\mathrm{b}}$ \\
\hline$(-\mathrm{Fe}+\mathrm{P})$ & $115.44 \pm 25.37^{\mathrm{c}}$ & $29.25 \pm 2.21^{\mathrm{a}}$ & $28 \pm 1.55^{\mathrm{c}}$ & $40.13 \pm 2.31^{\mathrm{c}}$ & $32.36 \pm 2.48^{\mathrm{b}}$ & $26.83 \pm 0.66^{\mathrm{c}}$ \\
\hline$(-\mathrm{Fe}-\mathrm{P})$ & $67.43 \pm 5.59^{\mathrm{d}}$ & $22.8 \pm 2.42^{\mathrm{b}}$ & $30.85 \pm 2.11^{\mathrm{c}}$ & $73.97 \pm 3.48^{\mathrm{d}}$ & $33.02 \pm 4.53^{\mathrm{b}}$ & $32.7 \pm 3.43^{\mathrm{b}}$ \\
\hline
\end{tabular}

Table 2: Effect of $\mathbf{P}$ deficiency on Fe responsive genes. Table shows the response to $\mathrm{Fe}$ starvation responsive genes under an additional starvation of $\mathrm{P}(-\mathrm{Fe}-\mathrm{P})$. (Up: upregulated; Down: Downregulated; no change: no significant differential expression under $\mathrm{Fe}-\mathrm{P}$ condition).

\begin{tabular}{ll|lc}
\hline \multicolumn{2}{l|}{$(-\mathbf{F e})$} & \multicolumn{3}{l}{} \\
\hline $\mathbf{( + P )}$ & & $(-\mathbf{P})$ & \\
\hline \multirow{3}{*}{$\mathrm{Up}$} & \multirow{2}{*}{2055} & $\begin{array}{l}\text { Down } \\
\text { no change }\end{array}$ & 1592 \\
\hline \multirow{3}{*}{ Down } & \multirow{2}{*}{2191} & Up & 115 \\
& & Down & 116 \\
& & no change & 1960 \\
\hline
\end{tabular}

Table 3: Percentage distribution of top twenty frequent putative cis-regulatory elements (freqpCREs) analyzed in the RNAseq data $(-\mathrm{Fe}+\mathrm{P},+\mathrm{Fe}-\mathrm{P},-\mathrm{Fe}-\mathrm{P})$ and in shortlisted genes involved during Fe-starvation response (FSR-93 genes) and phosphate starvation response (PSR-50 genes). Detailed list of freq-pCREs analysis is shown in Table S13.

\begin{tabular}{|c|c|c|c|c|c|c|}
\hline \multirow{2}{*}{$\begin{array}{l}\text { PCRE } \\
\text { motifs }\end{array}$} & \multicolumn{5}{|c|}{$\begin{array}{l}\text { Percentage distribution of freq-pCREs in given } \\
\text { condition }\end{array}$} & \multirow[b]{2}{*}{ Top TF family } \\
\hline & $-\mathbf{F e}+\mathbf{P}$ & $+\mathrm{Fe}-\mathrm{P}$ & $-\mathbf{F e}-\mathbf{P}$ & FSR & PSR & \\
\hline CATGCA & 63.82 & 62.22 & 65.79 & 79.57 & 80.00 & ABI3VP1 \\
\hline ATATAT & 65.87 & 66.42 & 67.52 & 68.82 & 70.00 & ARID \\
\hline GCATGA & 46.09 & 44.41 & 46.91 & 68.82 & 60.00 & B3 \\
\hline ATGCAT & 64.20 & 64.68 & 65.72 & 65.59 & 70.00 & B3 \\
\hline AATATG & 49.27 & 49.64 & 48.02 & 54.84 & 52.00 & G2-like \\
\hline AATTAA & 54.52 & 55.30 & 54.21 & 54.84 & 56.00 & Homeobox \\
\hline AAAGTA & 42.53 & 43.28 & 41.33 & 53.76 & 32.00 & C2C2-Dof \\
\hline
\end{tabular}




\begin{tabular}{|l|l|l|l|l|l|l|} 
AAACTA & 49.29 & 50.49 & 50.65 & $\mathbf{5 1 . 6 1}$ & 66.00 & ARID \\
\hline AGCATG & 44.21 & 44.65 & 45.07 & $\mathbf{5 1 . 6 1}$ & 52.00 & B3 \\
\hline TATGCA & 45.24 & 46.50 & 47.05 & $\mathbf{5 0 . 5 4}$ & 50.00 & ABI3VP1 \\
\hline AGGCAT & 33.58 & 34.35 & 33.71 & $\mathbf{4 8 . 3 9}$ & 38.00 & G2-like \\
\hline CCGGCC & 50.82 & 49.48 & 50.40 & $\mathbf{4 8 . 3 9}$ & 58.00 & GeBP \\
\hline ACTAGT & 43.24 & 41.80 & 41.73 & $\mathbf{4 7 . 3 1}$ & 32.00 & bHLH \\
\hline CACACG & 43.24 & 42.03 & 42.95 & $\mathbf{4 7 . 3 1}$ & 28.00 & BZR \\
\hline CGTGCC & 35.68 & 33.08 & 34.78 & $\mathbf{4 6 . 2 4}$ & 30.00 & bHLH \\
\hline TGTACA & 38.86 & 40.18 & 40.18 & $\mathbf{4 6 . 2 4}$ & 44.00 & NAC \\
\hline ACGGCA & 31.09 & 28.51 & 32.12 & $\mathbf{4 5 . 1 6}$ & 36.00 & NAC \\
\hline AGTCAA & 38.93 & 38.39 & 40.00 & $\mathbf{4 5 . 1 6}$ & 58.00 & WRKY \\
\hline TATAGA & 34.24 & 35.51 & 33.49 & $\mathbf{4 5 . 1 6}$ & 28.00 & Orphan \\
\hline GGCATGA & 12.46 & 11.73 & 12.01 & $\mathbf{4 4 . 0 9}$ & 8.00 & B3 \\
\hline
\end{tabular}

\section{Figure Legends}

Figure 1: Effect of Fe and $P$ on the growth of roots and shoots of wheat seedlings exposed to $+\mathrm{Fe}+\mathrm{P},+\mathrm{Fe}-\mathrm{P},-\mathrm{Fe}+\mathrm{P}$ and $-\mathrm{Fe}-\mathrm{P}$ after 20 days of treatment. (A) Experimental setup and the overall growth of wheat seedlings in the given conditions. Morphology of the wheat seedlings subjected to mentioned stress condition $(+\mathrm{Fe}+\mathrm{P},+\mathrm{Fe}-\mathrm{P},-\mathrm{Fe}+\mathrm{P}$ and $-\mathrm{Fe}-\mathrm{P})$. Pictures were taken after 20 days of treatment. (B) Primary root length of wheat seedlings under-treated conditions. (C) The total number of $1^{\text {st }}$ order lateral roots and (D) Average total length of lateral roots. (E) Dry weight biomass of the seedlings (grams/seedling) of 20 days old seedlings under different mentioned conditions. One-way ANOVA with Tukey's multiple comparison test means values was done. The different letters indicate a significant means difference, and the bars indicate SD ( $\mathrm{n}=8$ for B-E).

1114 Figure 2: Effect of Fe and $\mathbf{P}$ interaction on metal accumulation and its mobilization. (A) 1115 Phosphate concentration in roots and shoots of wheat seedlings under different regimes of Fe and $\mathrm{P}$, post 20 days of growth. (B) The phenotype of wheat root seedlings during the combinatorial effects of Fe and P as observed by Perl's Stain for iron plaque (blue plaques). (C) Estimation of the phytosiderophore (PS) release (Fe-solubilization) capacity by the wheat 
1119 roots under the mentioned condition. * and \# indicate means are significantly different at $\mathrm{p} \leq 0.05$ and $\mathrm{p} \leq 0.01$, respectively $(\mathrm{n}=8)$.

Figure 3: Transcriptome analysis of wheat roots grown under single $(-\mathbf{P},-\mathrm{Fe})$ and dual (1123 Fe-P) conditions. (A) Genes differentially expressed in response to different deficiency 1124 conditions (Fe and P deficiency: -Fe-P; P deficiency: +Fe-P; Fe deficiency: $-\mathrm{Fe}+\mathrm{P}$ ) with 1125 respect to control wheat roots $(+\mathrm{Fe}+\mathrm{P})$. (B) Venn diagram represents the number of unique and common differentially regulated genes for the three conditions compared to control. (C) Clustered heatmap analysis of highest differentially responsive genes (left: genes with the highest induction; right: fifty most repressed genes) during $-\mathrm{Fe}-\mathrm{P}$ condition in all three starvation conditions (combined deficiency: -Fe-P; P deficiency: -P; Fe deficiency: -Fe; Table $\mathrm{S} 3)$. Increasing intensities of red and blue colours represent up- and downregulation $\left(\log _{2} \mathrm{FC}\right)$, as depicted by the color scale.

Figure 4: Fe and $P$ deficiencyresponsive transcripts affected by different regimes of $P$ and Fe. (A) Response of phosphate starvation responsive (PSR) genes to respective conditions. In total 50 PSR genes related to Pi uptake, transport and regulation were shortlisted for the analysis. (B) Effect of additional P deficiency on Fe responsive genes (Table 1). The inner circle of the sunburst graph represents transcripts up-and downregulated under Fe stress, while the outer concentric circle represents the distribution of said these genes upon dual combined stress. (UP: upregulated; Down: Downregulated; Dual_no: not differentially expressed under Fe-P). (C) Heatmap depicting the response of 93 iron-responsive DEGs involved in Fe uptake, mobilization and regulation as identified earlier [13] during the three deficiency conditions. Red and blue bins represent up-regulation and down-regulation as represented by the scale. (D)KEGG pathway enrichment analysis for P deficiency responses w.r.t. Fe deficient wheat root transcriptome. Significantly enriched pathways (qvalue $<0.05$ ) for $+\mathrm{Fe}-\mathrm{P}$ w.r.t. $-\mathrm{Fe}+\mathrm{P} . \mathrm{x}-$ axis depicts the rich-factor, i.e., the ratio of perturbed genes in a pathway with respect to the total number of genes involved in the respective pathway, the y-axis represents the enriched pathway names, bubble sizes depict the number of genes altered in respective pathways, and increasing intensity of blue color represents increasing significance (decreasing q-value). 
1153 regulation and down-regulation as shown by the scale. (B) Significantly enriched pathways

1154 (qvalue< 0.05) for $-\mathrm{Fe}-\mathrm{P}$ (combined deficiency) compared to $+\mathrm{Fe}+\mathrm{P}$ (control). Significantly

1155 enriched pathways (qvalue< 0.05) for $-\mathrm{Fe}-\mathrm{P}$ (combined deficiency) compared to $-\mathrm{Fe}+\mathrm{P}$ ( $\mathrm{Fe}$

1156 deficiency). Significantly enriched pathways (qvalue< 0.05 ) for $-\mathrm{Fe}-\mathrm{P}$ (combined deficiency)

1157 and $+\mathrm{Fe}-\mathrm{P}$ (P deficiency). $\mathrm{x}$-axis depicts the rich-factor, i.e., the ratio of perturbed genes in a

1158 pathway with respect to the total number of genes involved in the respective pathway, the $y$ -

1159 axis represents the enriched pathway names, bubble sizes depict the number of genes altered in

1160 respective pathways and increasing intensity of the color represents increasing significance (q-

1161 value).

1162 Figure 6: Overview of the changes in metabolome in roots of wheat seedlings subjected to

1163 different growth regimes of Fe and P. (A) GC-MS based heatmap comparison of root

1164 metabolites in $+\mathrm{Fe}+\mathrm{P} ;-\mathrm{Fe}+\mathrm{P} ;+\mathrm{Fe}-\mathrm{P}$ and $-\mathrm{Fe}-\mathrm{P}$ condition. Metabolites are sorted according

1165 to their classes, specifically, sugars, general acids, amino acids, sugar conjugates, fatty acids

1166 and polyols. Concentrations $(\mu \mathrm{g} / \mathrm{mg}$, fresh weight) of individual metabolites in test conditions

1167 were compared with control metabolite concentrations and represented with $\log _{2} \mathrm{FC}$ values as

1168 shown by the scale. Data means \pm SD of $n=3$ experiments. (B) Quantitative plot for the

1169 metabolite concentrations ( $\mu \mathrm{g} / \mathrm{mg} \mathrm{FW}$ ) for response specific to $-\mathrm{Fe}-\mathrm{P}$ and response common

1170 in $-\mathrm{Fe}$ and -Fe-P. Different symbols indicate significant differences between the conditions

1171 determined by Fisher's LSD $(\mathrm{p}<0.05)$. +Fe +P, control; -Fe +P, Fe deficiency; +Fe -P, P

1172 deficiency; -Fe -P, Fe and P deficiency. 'a' represents a significant difference against control,

1173 '\#' represents significant difference against Fe deficiency and '@' represents significant

1174 difference against $\mathrm{P}$ deficiency. 
(A)

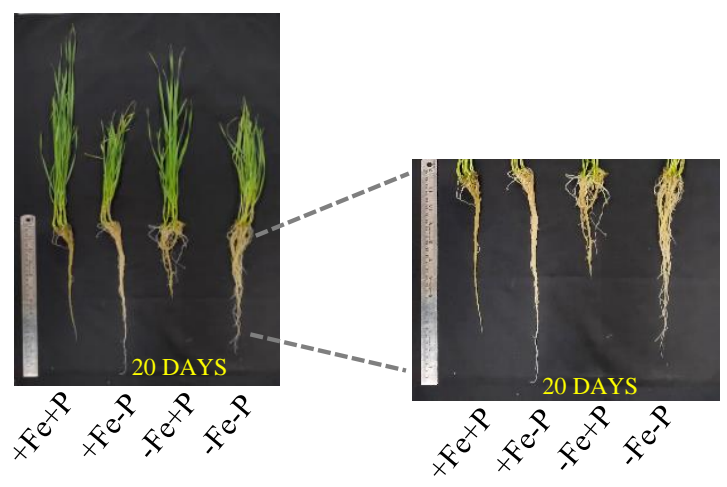

(C)

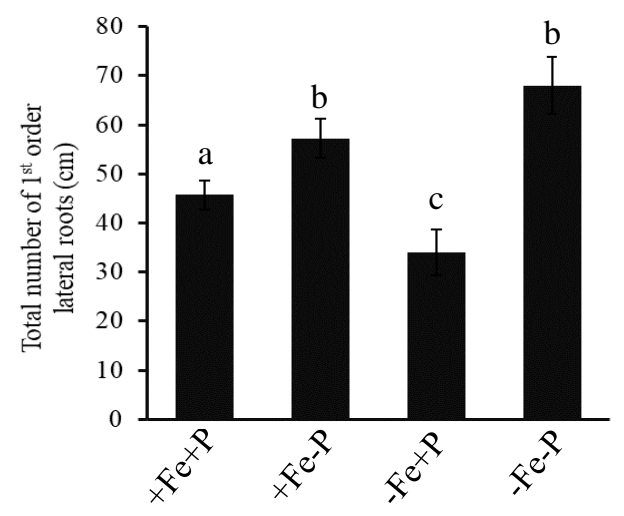

(E)

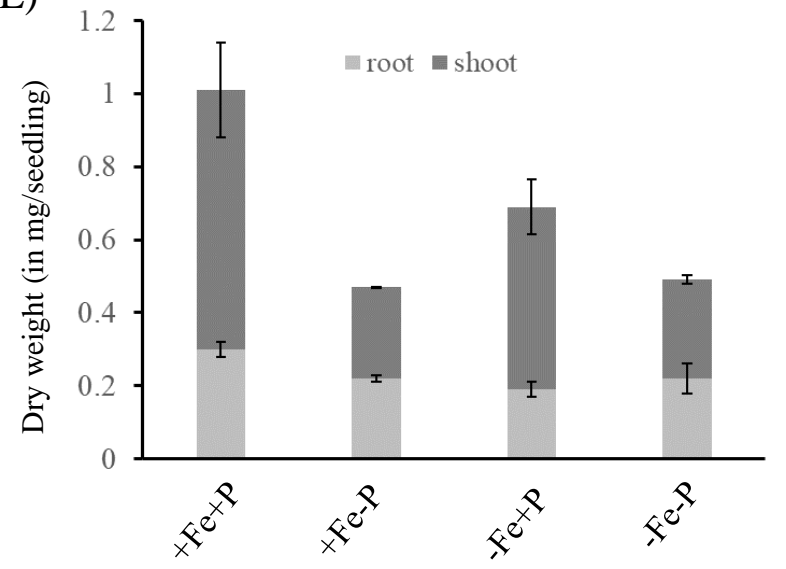

(B)

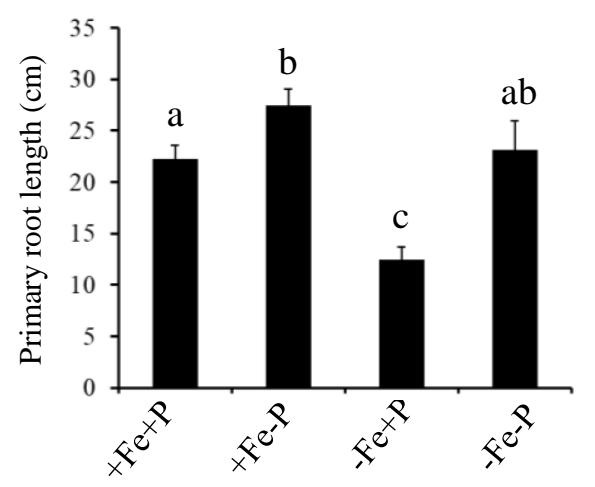

(D)

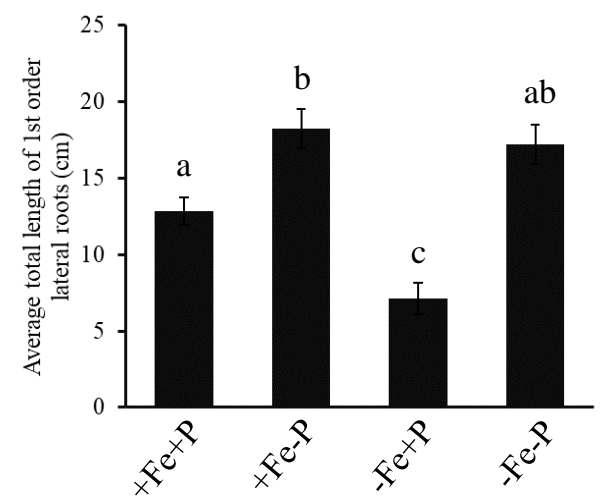

Figure 1 
(A)

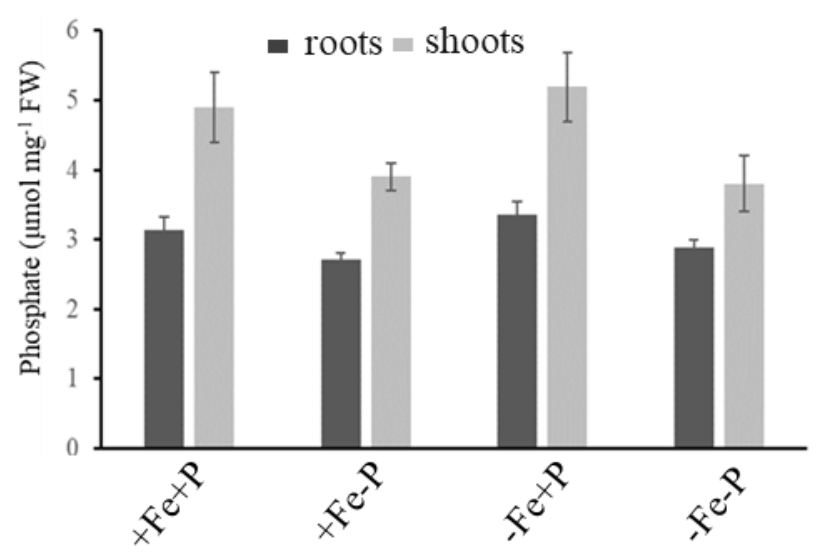

(C)

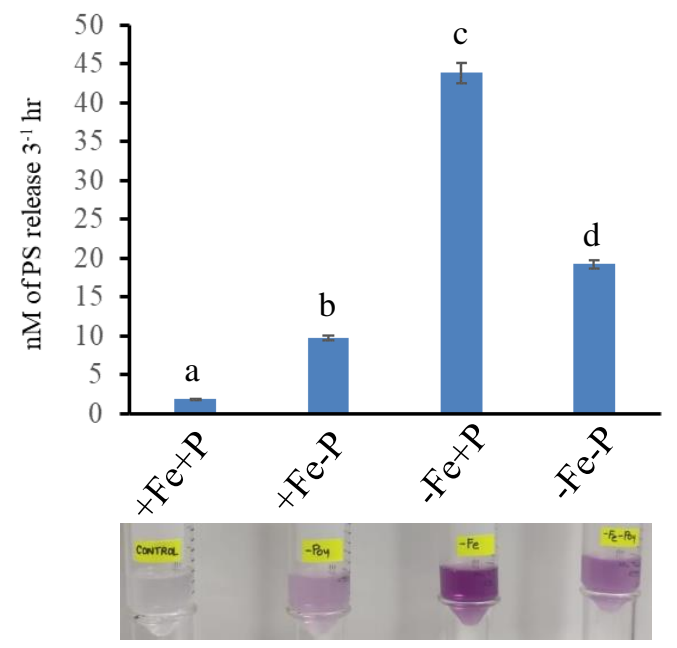

(B)

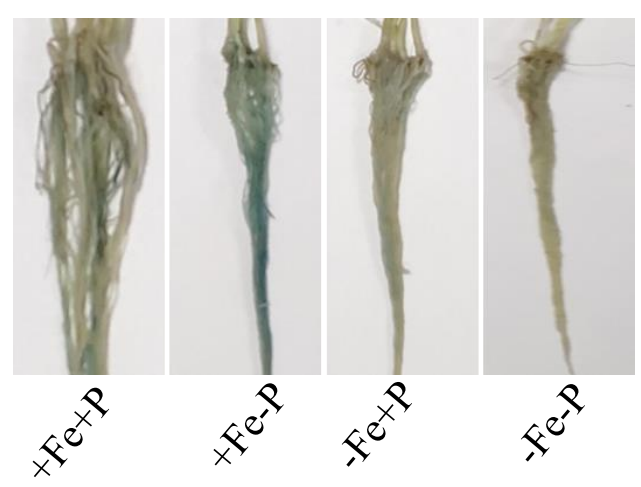

Figure 2 
(which was not certified by peer review) is the author/funder, who has granted bioRxiv a license to display the preprint in perpetuity. It is $m$ available under aCC-BY-NC-ND 4.0 International license.

(A)

\section{Upregulated Downregulated}

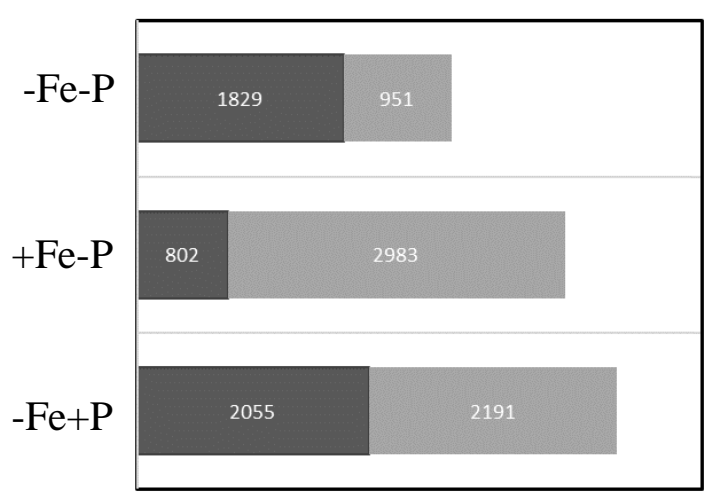

(C)

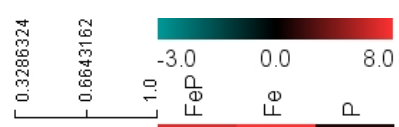

Protein ZINC INDUCED FACILITATOR-LIKE 1 Malate dehydrogenase Malate dehydrogenase
Protein ZINC INDUCED FACILITATOR-LIKE 1
Protein ZINC INDUCED FACILITATOR-LIKE 1 formate dehydrogenase
Nicotianamine synthase

Nicotianamine synthase
Aminotransferase-related family protein

Aminotransferase-related family protein
Nicotianamine synthase
Protein ZINC INDUCED FACILITATOR-LIKE

Nicotianamine synthase

Nicotianamine synthase

Protein ZINC INDUCED FACILITA
V-type ATP synthase alpha chain

Aldolase superfamily protein

Nicotianamine synthase

Nicotianamine synthase
Nicotianamine synthase

Aminotransferase-related family protein

Aminotransine synthas

Protein ZINC INDUCED FACILITATOR-LIKE 1

Nicotianamine synthase

Basic helix-loop-helix (BHLH) family transcription factor

Nicotianamine synthase

Nicotianamine synthase
Nicotianamine synthase

Nicotianamine synthase

Nicotianamine symase

Nicotianamine synthase

Aminotransferase-related family prote

Nicotianamine synthase

basic helix-loop-helix (bHLH) DNA-binding superfamily protein

Nicotianamine synthase

Dirigent protein

Dirigent protein
Abscisic stress ripening protein

Abscisic stress ripening protein

Chemotaxis response regulator protein-glutamate methylesterase 1

Dirigent protein

Glutathione S-transferas

ALWAYS EARLY

Nuclease $\$ 1$
UBiQuitin family member

chlorophyll A/B-binding protein 2

Cytochrome P450

DNA mismatch repair protein muts
(B)
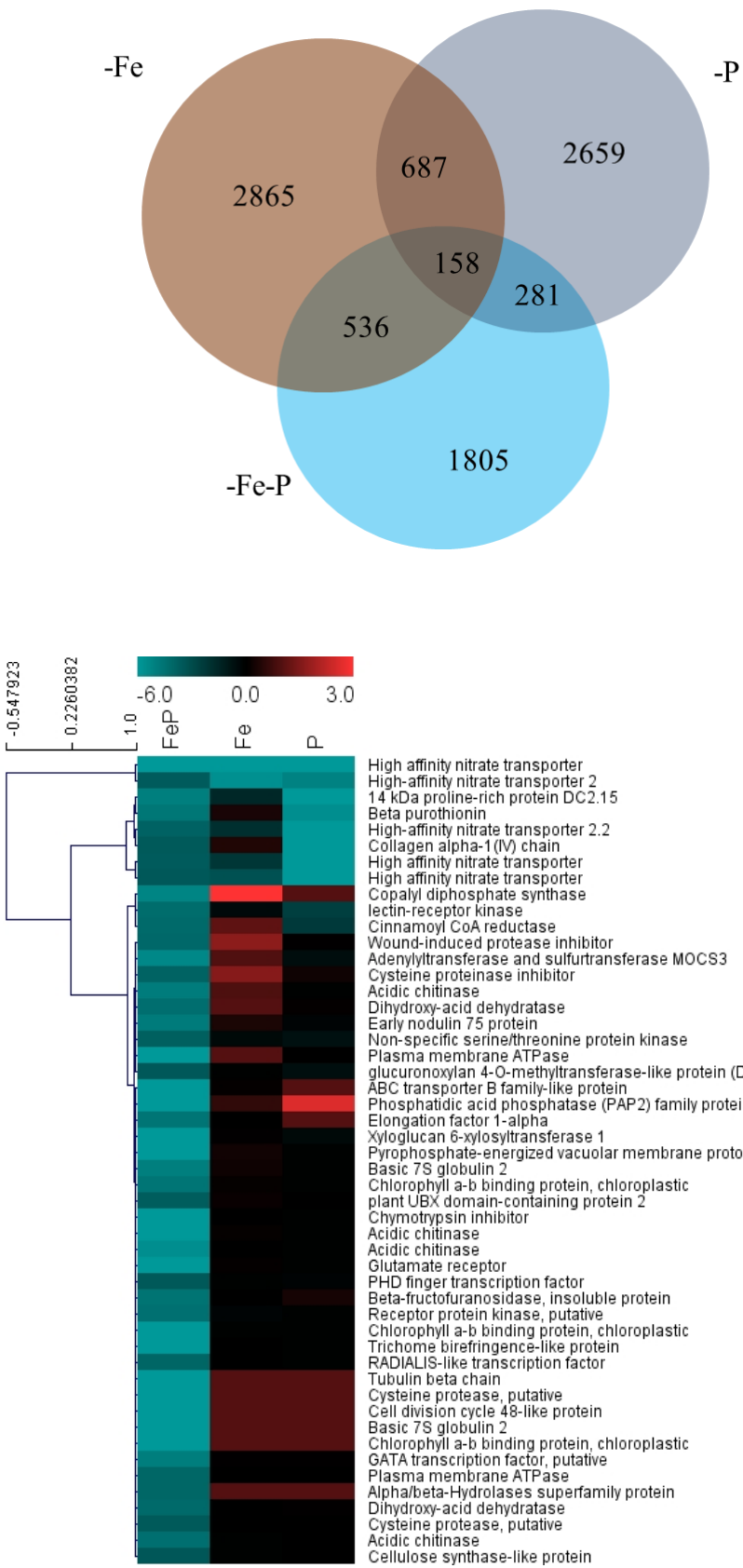

High affinity nitrate transporte High-affinity nitrate transporter 2 Beta purothionin

High-affinity nitrate transporter 2.2

Collagen alpha-1 (IV) chain

High affinity nitrate transporter

Copalyl diphosphate synthas

lectin-receptor kinase

Wound-induced protease inhibitor

Adenylyltransferase and sulfurtransferase MOCS

Cysteine proteinase inhibitor

Acidic chitinase

Dihydroxy-acid dehydratas

Non-specific serinelthreonine protein kinase

Plasma membrane ATPase
glucuronoxylan 4-0-methyltransferase-like protein (DUF579)

ABC transporter B family-like protein 2 ) family protein

Phosphatidic acid phosph
Elongation factor 1-alpha

Xyloglucan 6-xylosyltransferase

Pyrophosphate-energized vacuolar membrane proton pump

Basic 7S globulin 2

Chlorophyll a-b binding protein, chloroplastic

Chymotrypsin inhibitor

Acidic chitinase

Acidic chitinase

Glutamate receptor

Beta-fructofuranosidase, insoluble protein

Receptor protein kinase, putative Trichome birefringence-like protein
RADIALIS-like transcription factor

Tubulin beta chain

Tubulin beta chain

Cell division cycle 48-like protein

Chlorophyll $\mathrm{a}-\mathrm{b}$ binding protein, chloroplastic

GATA transcription factor, putativ

Alpha/beta-Hydrolases superfamily protein

Dihydroxy-acid dehydratase

Cysteine protease, putative

Acidic chitinase

Figure 3 
(A)
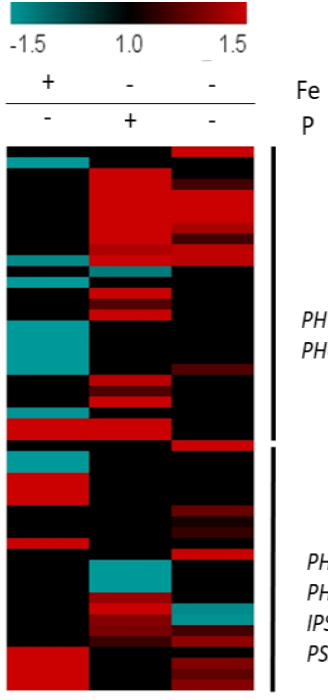

PHR
PHF
IPS1
PS2

(C)
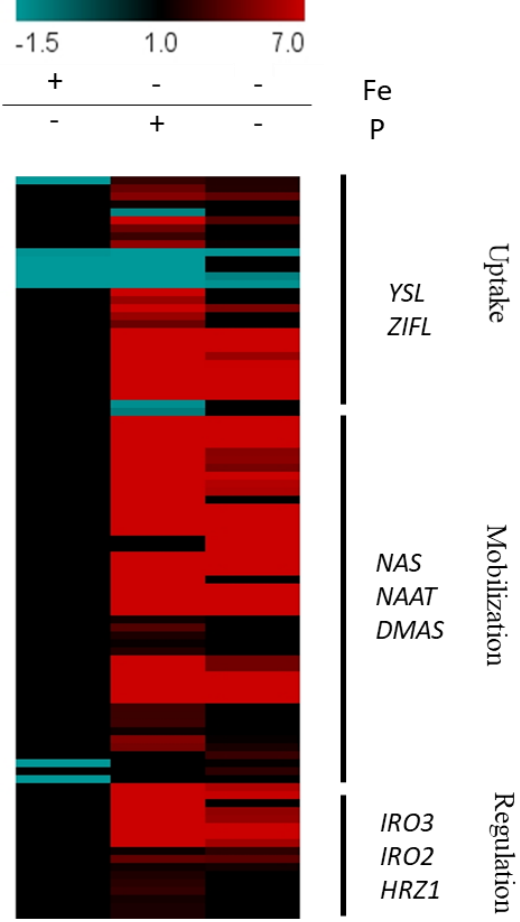

(B)

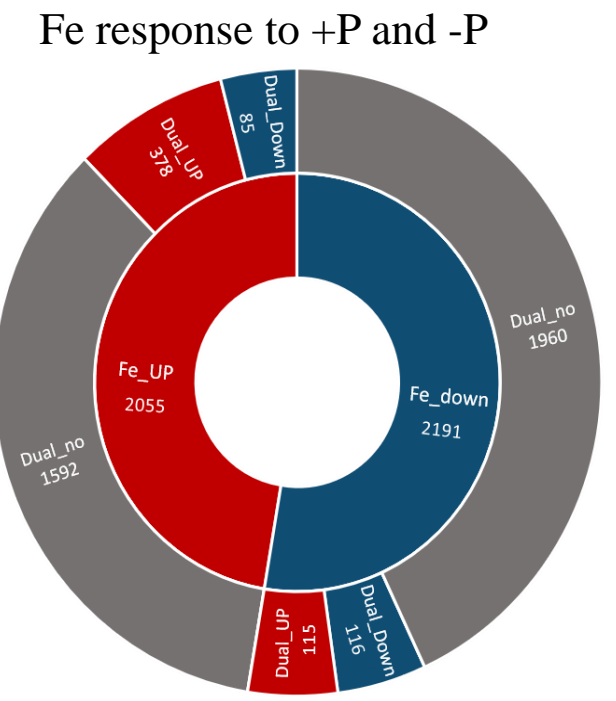

(D)

$$
\text { -P vs-FE }
$$

Selenocompound Metabolism

Ribosome

Porphyrin and chlorophyll Photosynthesis - antenna proteins Photosynthesis

Phenylpropanoid biosynthesis Nitrogen metabolism MAPK signaling pathway - plant . Glyoxylate and dicarboxylate metabolism

Glutathione metabolism

Diterpenoid biosynthesis Cysteine and methionine metabolism

Cyanoamino acid metabolism . Carbon metabolism . Carbon fixation in photosynthetic organisms .

Biosynthesis of amino acids . Alanine, aspartate and glutamate metabolism

Gene_number qvalue $\quad \begin{array}{llll}0.1 & \begin{array}{c}0.2 \\ \text { rich_factor }\end{array} & 0.4\end{array}$

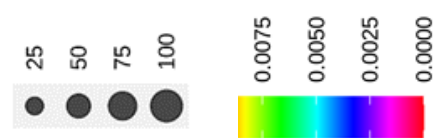

Figure 4 
(A)
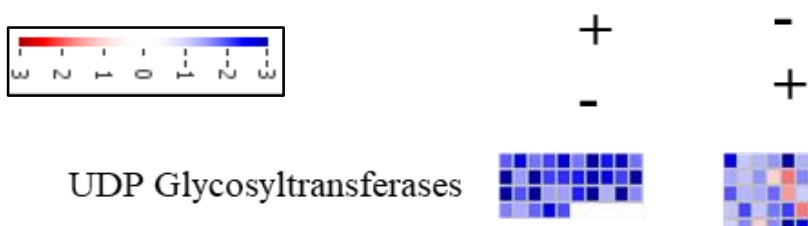

- $\mathrm{Fe}$

UDP Glycosyltransferases
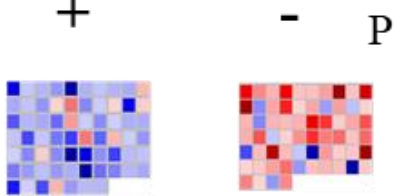

Cytochrome P450
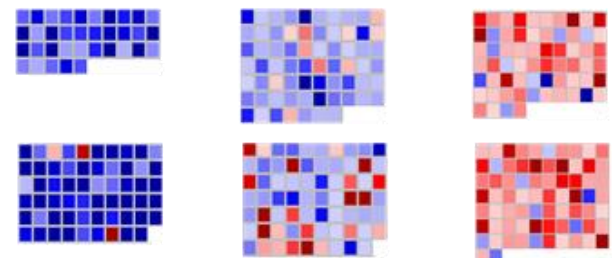

Glutathione-S-transferases
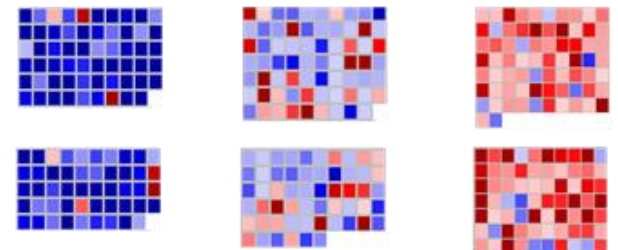

(B)

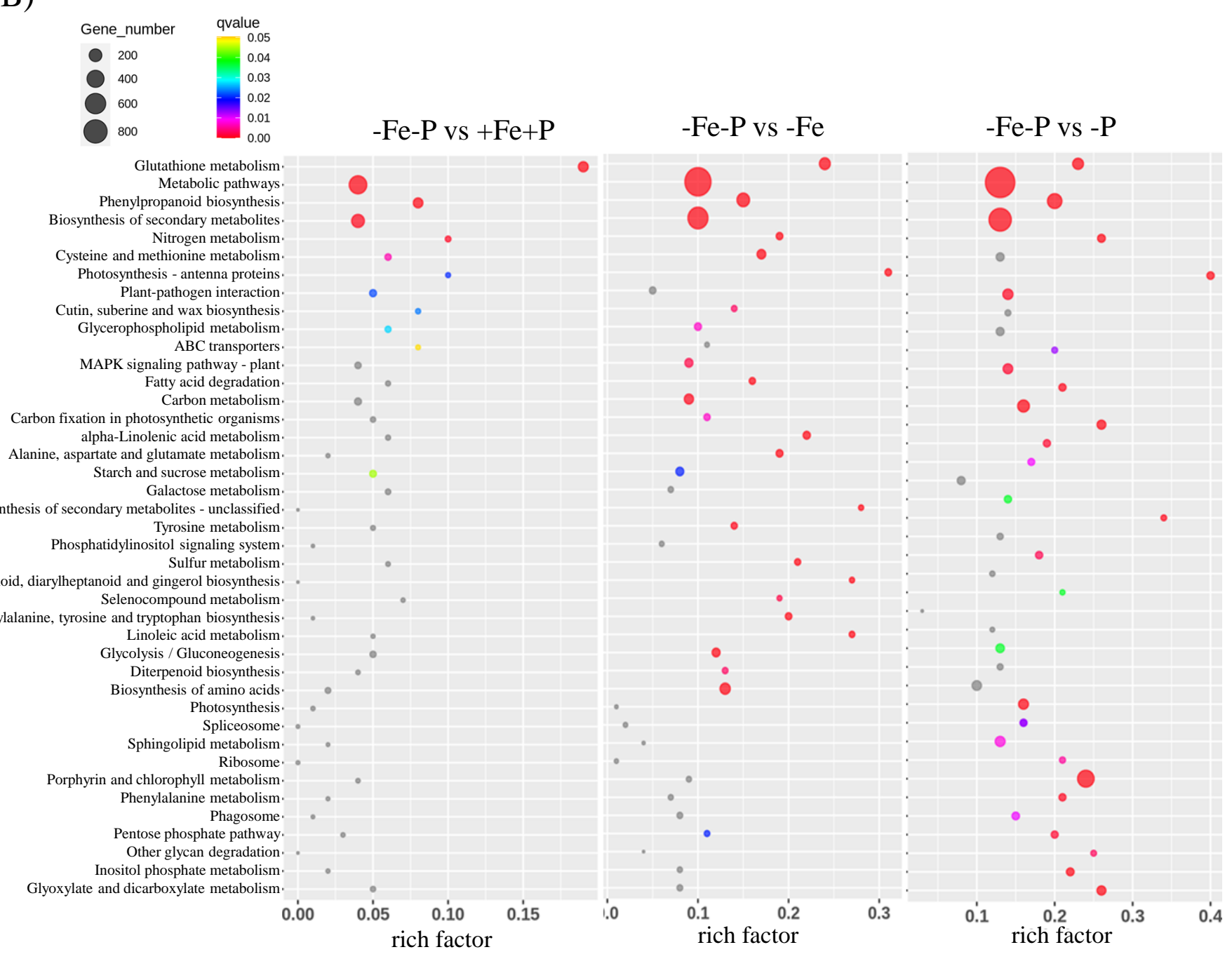

\section{Figure 5}


(A)
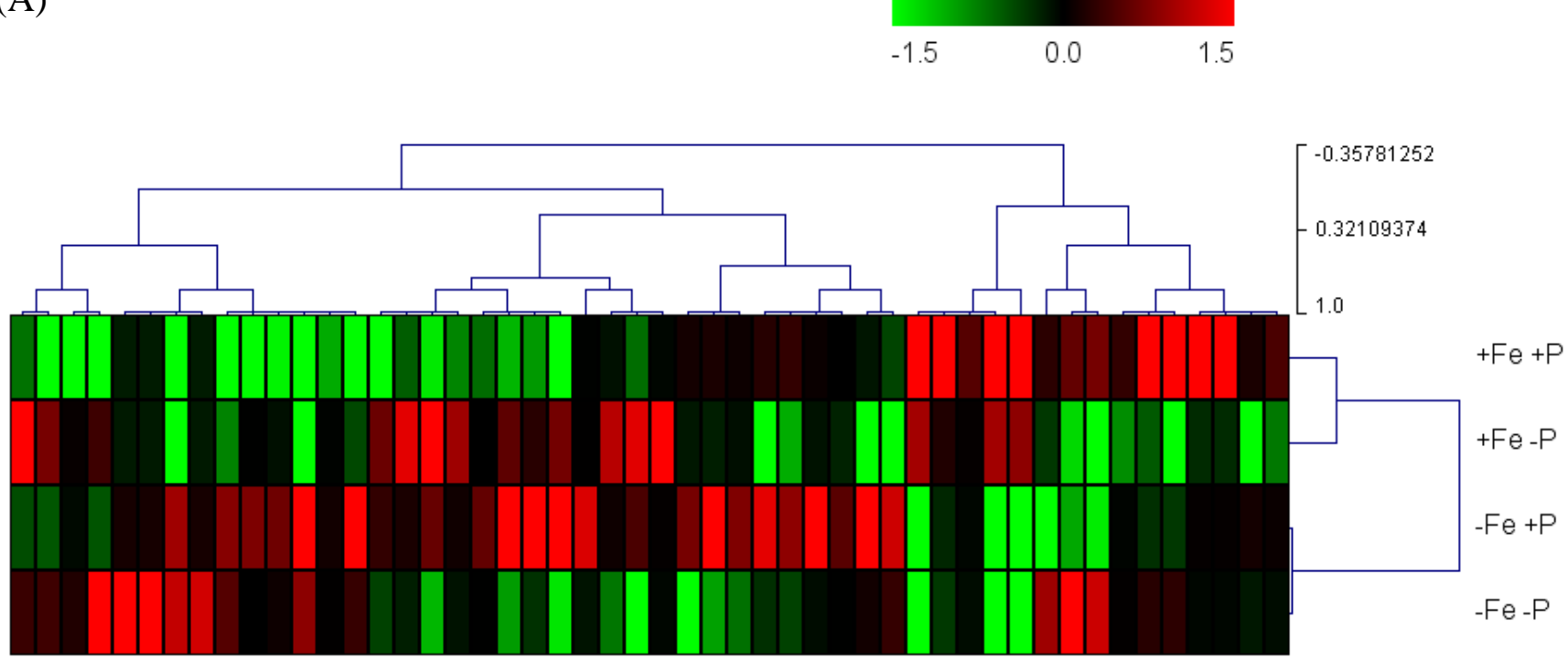

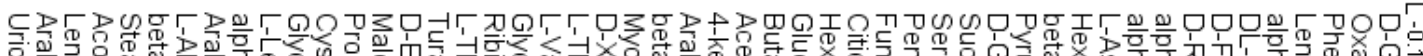

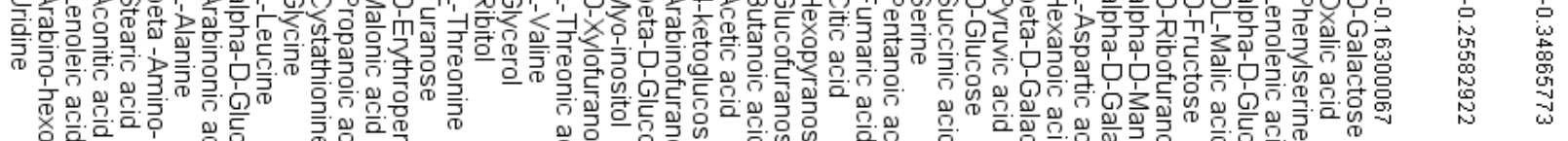

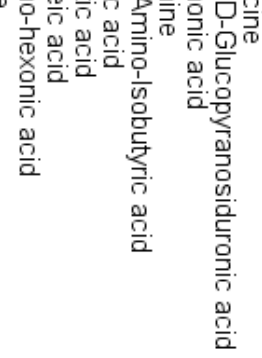

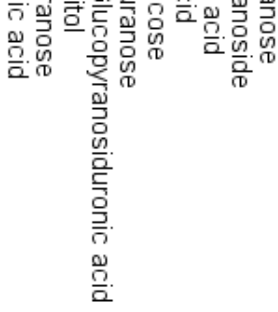

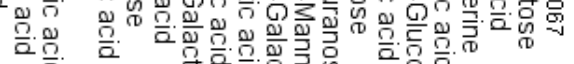

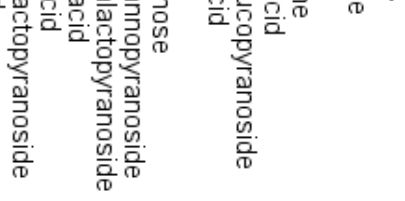

(B)

Response specific to $-\mathrm{Fe}-\mathrm{P}$

Response common for $-\mathrm{Fe}$ and $-\mathrm{Fe}-\mathrm{P}$


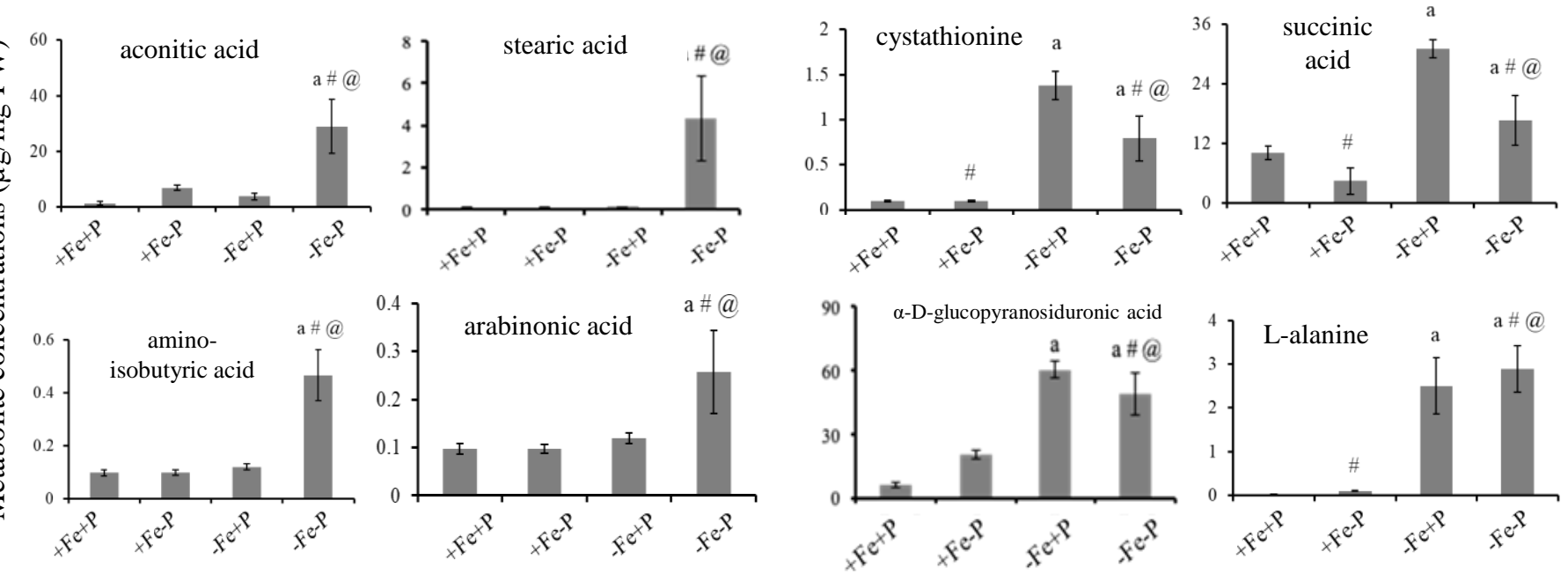

Figure 6 